VOL. 64, NO. 4, APRIL 1993
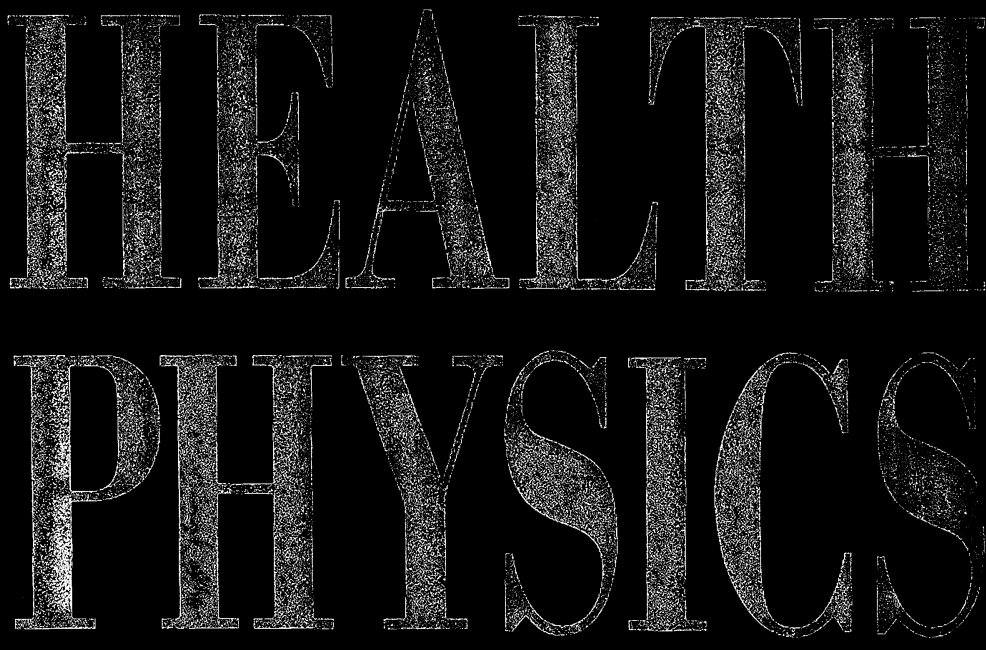

THE RADIATION PROTECTION JOURNAL
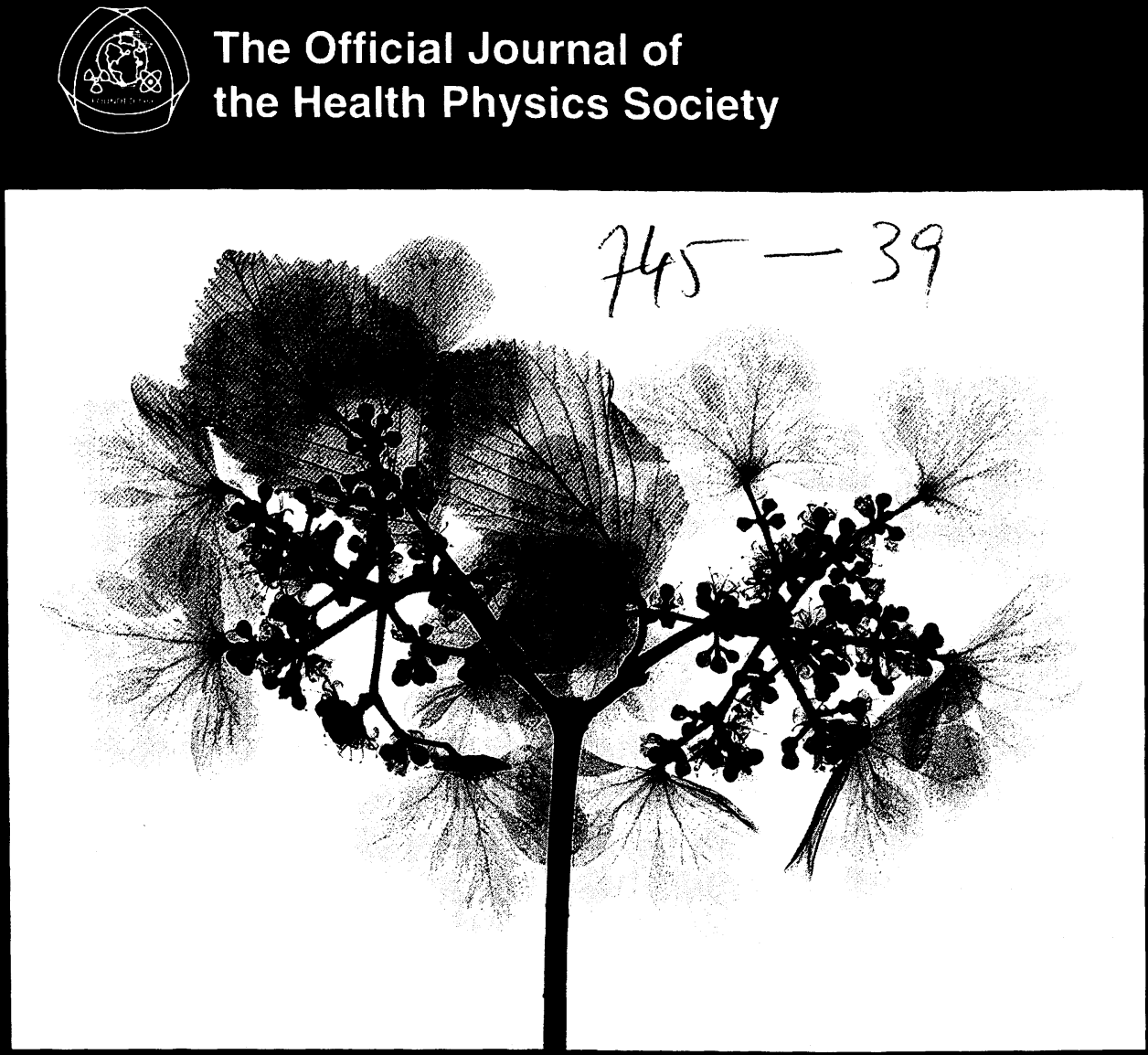


\section{HEALTH PHYSICS \\ The Radiation Protection Journal}

\section{CONTENTS}

\section{PAPERS}

Breast Cancer Incidence at a Nuclear Facility: Demonstration of a

Morbidity Surveillance System

Thomas L. Vaughan, John A. H. Lee, and

Clifton H. Strader

A Survey of the Czechoslovak Follow-up of Lung Cancer Mortality in Uranium Miners

J. Sevc, L. Tomásek, E. Kunz, V. Placek,

D. Chmelevsky, D. Barclay, and A. M. Kellerer

355

Prospective Study of the Clinical Symptoms of Therapeutic Whole

Body Irradiation

M. P. Chaillet, J. M. Cosset, G. Socie, J. L. Pico,

E. Grimaud, B. Dubray, C. Alapetite, and T. Girinsky

Diagnostic Radiopharmaceutical Dose Estimate to the Australian Population

Silvano F. Colmanet and David L. Samuels

Estimating Past Exposure to Indoor Radon from Household Glass J. A. Mahaffey, M. A. Parkhurst, A. C. James,

F. T. Cross, M. C. R. Alavanja, J. D. Boice, S. Ezrine,

P. Henderson, and R. C. Brownson

Airborne ${ }^{222}$ Rn Concentration in Cypriot Houses

Stelios Christofides and George Christodoulides

Electret Ion Chamber Radon Monitors Measure Dissolved ${ }^{222} \mathbf{R n}$ in Water

P. Kotrappa and W. A. Jester

A Comparison of Techniques in the Assessment of Chest Wall

Thickness and Composition

C. Kang, D. Newton, A. J. Warner, T. A. Absolom,

D. A. Kruchten, A. L. Anderson, and H. E. Palmer

Evaluation of a New High-Density Shielding Material

Robet J. Barish

FORUM

The Scientific Base for the Disposal of Spent Nuclear Fuel Lars Persson

NOTES

Preliminary Indoor Radon Investigations in Lubin Region, Poland J. Vaupotič, M. Szymula, J. Solecki, S. Chibowski, and

I. Kotal
Initial Study of ${ }^{210} \mathrm{~Pb}$ in Indoor Air

Isabel M. Fisenne

423

\section{OPERATIONAL TOPICS}

Verification of Aquatic Dilution Factors for Liquid Effluents Released from a Nuclear Power Plant

Ihab R. Kamel, Thomas J. VanderMey, and

Suellen K. Cook

\section{CORRESPONDENCE}

Misstatement on Radium Dial Workers by Puskin et al.

Robert G. Thomas

Reply to Thomas

Neal S. Nelson, Jerome S. Puskin, and

Christopher B. Nelson

Standardizing Minimum Detectable Amount Formulations

Allen Brodsky

Comparison of Criteria to Define Radon-Prone Areas

A. G. Scott

1990 Recommendations of the ICRP

Charles B. Meinhold and Ralph Thomas

\section{BOOK REVIEWS}

Phosphorus-32: Practical Radiation Protection Tritium: Radiation Protection in the Laboratory

Reviewed by William C. Reinig

Dosimetry of Ionizing Radiation, Volume III

Reviewed by K. J. Kearfott

Introductory Physics of Nuclear Medicine

Reviewed by K. J. Kearfott

Screen Film Mammography: Imaging Considerations and Medical Physics Responsibilities

Reviewed by K. J. Kearfott

Expanding the Role of Medical Physics in Nuclear Medicine Reviewed by K. J. Kearfott 


\section{CONTENTS (continued)}

Radon 2000

Reviewed by Edwin L. Sensintaffar

Computers in Medical Physics

Reviewed by Timothy H. Fox and Patton H. McGinley

The Secret Garden

Reviewed by James M. Kofler, Jr.

\section{OTHER CONTENT}

Errata

News and Notices

New Products

Instructions to Contributors

Health Physics Society Prospectus

Health Physics Society Affiliate Members

444

441

Advertiser Guide Appears at the back of this issue

441

Advertiser Index

Up and Coming

442

452

453

455
On the cover: Radiograph of the Viburnum flower. From The Secret Garden by Albert G. Richards. See book review by J. M. Kofler, Jr. on p. 442 for more details! 


\title{
A SURVEY OF THE CZECHOSLOVAK FOLLOW-UP OF LUNG CANCER MORTALITY IN URANIUM MINERS*
}

\author{
J. Sevc, ${ }^{\ddagger}$ L. Tomasek, ${ }^{\ddagger}$ E. Kunz, ${ }^{\ddagger}$ V. Placek, ${ }^{\S}$ D. Chmelevsky, ${ }^{\Perp}$ D. Barclay, ${ }^{\Perp}$ and \\ A. M. Kellerer ${ }^{\text {\#\# }}$
}

\begin{abstract}
The major Czechoslovak cohort of uranium miners (S-cohort) is surveyed in terms of diagrams illustrating dependences on calendar year, age, and exposure to radon and radon progeny. An analysis of the dose dependence of lung cancer mortality is performed by nonparametric and, subsequently, by parametric methods. In the first step, two-dimensional isotonic regression is employed to derive the lung cancer mortality rate and the relative excess risk as functions of age attained and of lagged cumulated exposure. In a second step, analytical fits in terms of relative risk models are derived. The treatment is largely analogous to the methods applied by the BEIR IV Committee to other major cohorts of uranium miners. There is a marked dependence of the excess risk on age attained and on time since exposure. A specific characteristic of the Czechoslovak data is the nonlinearity of the dependence of the lung cancer excess risk on the cumulated exposure; exposures on the order of 100 working level months or less appear to be more effective per working level month than larger exposures but, in the absence of an internal control group, this cannot be excluded to be due to confounders such as smoking or environmental exposures. A further notable observation is the association of larger excess risks with longer protraction of the exposures.

Health Phys. 64(4):355-369; 1993
\end{abstract}

Key words: uranium mines; mortality; lungs, human; radon

\section{INTRODUCTION}

THE LUNG cancer mortality risk from the inhalation of radon and its progeny has considerable importance with (H).

*Work supported by Euratom: B17-0007.C and B16.347.UK

† This paper had to be finished without its first author, who initiated and then led and organized the entire epidemiological study from its very beginning in 1970, and also took substantial active part in the jointly performed analysis. Dr. Josef Sevc, born 3 March 1932, died on 21 March 1991. He was the head of the epidemiological research group of the Centre of Radiation Hygiene of IHE in Prague. He founded and directed (1960-1969) the Institute for Industrial Hygiene of the Uranium Industry in Pribram.

${ }^{\ddagger}$ Institute for Hygiene and Epidemiology, 10042 Praha 10, Czechoslovakia; ${ }^{\S}$ Institute for Industrial Hygiene of the Uranium Industry, Pribram; "Institute for Radiation Protection, GSF, Neuherberg; ' Radiobiological Institute, University of Munich; * Institute for Radiobiology, GSF, Neuherberg.

(Manuscript received 10 December 1991; revised manuscript received 14 August 1992, accepted 19 October 1992)

$0017-9078 / 93 / \$ 3.00 / 0$

Copyright $@ 1993$ Health Physics Society regard to occupational and domestic exposures. Reports by the ICRP (1986) and by a committee assembled by the National Research Council (BEIR IV 1988) review available data and give risk estimates. The BEIR IV Committee has undertaken a joint analysis of four major cohorts of miners who were exposed to elevated levels of radon and its progeny. At the time, it was not yet possible to include the data from the Czechoslovak study in the analysis and the comparison could, therefore, relate only to the published results of this study (Sevc et al. 1976, 1983, 1986, 1988; Horacek et al. 1977; Kunz et al. 1978, 1979).

A more detailed comparison in terms of the same mathematical methods that were employed by the BEIR IV Committee (NRC 1988) is still desirable and by now possible. In this report, general characteristics of the follow-up of the principal Czechoslovak cohort of uranium miners are presented to facilitate insight into a complex data set. Diagrams bring out major aspects of the data for an eventual comparison with analogous information from other cohorts. The second part of the article includes, as an initial step, a nonparametric determination of the age-specific rates of lung cancer mortality in their dependence on cumulated exposure; this uses the method of isotonic regression in two dimensions (Barlow et al. 1972). A final section deals with analytical fits in terms of relative risk regression models. As in the BEIR IV analyses, it uses the computer program AMFIT which is part of the software package EPICURE.** The treatment is exploratory, and more explicit analyses of the nonlinearity of the dose dependence and of the influence of the temporal distribution of exposure may again be the objective of a joint treatment of the major studies from different countries.

\section{HISTORY OF THE CZECHOSLOVAK STUDY}

Several cohorts of miners are presently followed in Czechoslovakia. The oldest, the S-cohort, includes uranium miners who began mining between 1948 and 1957. The study was started in 1970 . Two other cohorts

** Preston, D. L.; Lubin, J. H.; Pierce, D. A. EPICURE, Generalized regression models for epidemiological data, software from Hirosoft International, Suite 103, 1463 E Republican, Seattle, WA 98112. 
were defined later. One consists of miners in burnt clay mines in Middle Bohemia (L-cohort). The other consists of uranium miners who started work after 1968 (N-cohort) under considerably lower exposure levels. Table 1 gives basic information about the various cohorts. For more detailed information, the reader is referred to previous publications [Kunz et al. 1978, 1979; Sevc et al. 1976, 1988 (in press); Horàcek et al. 1977].

Only the S-cohort, i.e., the cohort with the longest mean follow-up, is the object of the present analysis. The S-cohort study was started after the first observation of a statistically significant excess of lung cancer cases among the uranium miners in Joachimsthal. However, in view of the high rate of lung cancers in miners, autopsies had been performed even before World War $\mathrm{II}^{\dagger+}$ and lung cancer had been identified with the 'Bergkrankheit' (mine disease) that Georg Bauer, working as physician and mineralogist in the region in the first half of the 16th century, had described as a common fate of the miners in his most famous work 'De re metallica' (Agricola 1950).

A registry of the employees in the uranium mines of Western Bohemia established a cohort ${ }^{\ddagger \ddagger}$ with some 95,000 entries; $42.5 \%$ of these entries concerned underground miners. Criteria for inclusion in the cohort were as follows:

- Underground work starting between 1 January 1948 and 31 December 1957;

- Work underground for 4 y or more;

- Availability of personal and work description data; and

- Residence in Czechoslovakia.

These conditions were originally fulfilled by 4,361 miners, but periodic checks of the list for errors and duplications and losses due to emigration decreased the number to 4,042 . Later, it was discovered that 16 miners were included in the study who had not worked for four full years. In spite of the missing 2 or $3 \mathrm{mo}$, they were left in the study.

The condition of a minimum of $4 \mathrm{y}$ of underground work was adopted in view of a large number of persons who worked in the mines only for brief time periods and for whom available information was often

${ }^{\dagger+}$ Müller, J. Lung cancer caused by ionizing radiation, paper read at the Meeting on Epidemiological Studies in Human Radiobiology, sponsored by WHO, Washington, DC, 13-17 December 1965.

$\ddagger \ddagger$ The cohort includes only volunteer miners. insufficient. This relates partly to the fact that, at the time, only those with at least 4 y underground work had the possibility to have lung cancer recognized as occupational disease. In the subsequent analysis, miners are considered to be at risk $4 \mathrm{y}$ after beginning work underground. The condition of more than $4 \mathrm{y}$ of underground work implies that deaths within this period are not considered. Two lung cancer deaths happened at the end of the fifth year after start of mining; they are included in the subsequent analysis.

Most of the miners came to the region of Jachymov for this work. Only a minority originated from the region. "Original" houses in the Jachymov region tended to have high levels of radon; this is less so for houses specially built for miners in the area. In a random sample of about 400 miners of the S-cohort, only $11 \%$ had an address in either Jachymov or neighboring villages where higher radon concentrations occur. Therefore, it does not appear that, on the average, the miners have received significant radon exposure from the environment in addition to their occupational exposure. These considerations are relevant, as will be seen later on, to the observed nonlinearity of the lung cancer response vs. cumulated exposure.

To identify lung cancer cases that were diagnosed before the start of the study among cohort members, a well-kept registry of lung cancers among all miners was used that was established by the National Health Institute for Uranium Industry (a complex of all curative and preventive medicine institutions for this branch of industry that belongs to the Czechoslovak Ministry of Health). The registry also included retired miners and has been supplemented by data from various health institutions throughout the country with which the Institute had periodic contact.

The list of cases was verified by comparison with the information from the entirety of cancer notification cards from the national registry of malignant diseases. The cards are collected in line with the national policy of mandatory reporting of cancer, and they serve as a basis for yearly reports by the National Cancer Registry. For the later follow-up, the general national registry at the Ministry of the Interior, the local registries of inhabitants, and, especially, the local registries of death certificates were used, as well as available information from medical departments. These were the sources of information about deaths and other important changes

Table 1. The major Czechoslovak cohorts of miners that were exposed to elevated levels of radon progeny.

\begin{tabular}{cccccccccc}
\hline Cohort & $\begin{array}{c}\text { Start of } \\
\text { work }\end{array}$ & $\begin{array}{c}\text { Period of } \\
\text { follow-up }\end{array}$ & $\begin{array}{c}\text { Number of } \\
\text { miners }\end{array}$ & $\begin{array}{c}\text { Person } \\
\text { years }\end{array}$ & $\begin{array}{c}\text { Observed } \\
\text { cases }\end{array}$ & $\begin{array}{c}\text { Expected } \\
\text { cases }\end{array}$ & $\begin{array}{c}\text { Mean cu- } \\
\text { mulated } \\
\text { exposure } \\
\text { (WLM) }\end{array}$ & $\begin{array}{c}\text { Mean dura- } \\
\text { tion of em- } \\
\text { ployment (y) }\end{array}$ & $\begin{array}{c}\text { Mean age at } \\
\text { start (y) }\end{array}$ \\
\hline S & $1948-1957$ & $1953-1985$ & 4,042 & 97,913 & 574 & 122 & 227 & 8.2 & 32.4 \\
L & $1945-1980$ & $1960-1984$ & 916 & 16,747 & 25 & 18 & 25.6 & 12.3 & 31.0 \\
N & $1968-1976$ & $1970-1985$ & 5,557 & 55,779 & 7 & 8 & 6.2 & 5.6 & 24.0 \\
\hline
\end{tabular}


(e.g., emigration) within the S-cohort during its continued follow-up.

For assessing the individual accumulated exposure of the miners, some 120,000 results of radon measurements were available. From 1948 to 1970 , the average annual number of measurements in a mine increased from $\sim 100$ to $\sim 700$. For the computation of exposures in working level months (WLM), the equilibrium state of radon and its daughter products was required. It was assessed on the basis of radon daughter measurements that were introduced gradually in the years after 1960; the assessment was also partly based on knowledge of the evolution of mining technology and of the changing ventilation systems since 1948 .

Preliminary results from a revision of all individual exposures indicate that, for the first 2 y of mining, estimates of the individual exposures may contain errors. These 2 y represent, however, only $3 \%$ of the total person years at work, and preliminary calculations show that the subsequent results are not significantly affected by these errors.

The data in the present article relate to the status of the follow-up in 1985. At this point, approximately one-half of the initial cohort was still alive, and the mean age of the miners was $62 \mathrm{y}$ with a standard deviation of $8 \mathrm{y}$. The initial diagrams give information on the S-cohort, in dependence on calendar years.

Fig. 1 gives the number of miners at work during the specified calendar years and the number of miners under observation in the cohort. As stated, the followup starts only 4 y after the start of employment. Fig. 2 indicates the aging of the cohort during the follow-up time period. Fig. 3 gives the mean annual exposure received by the miners during the specified calendar years and the mean cumulated exposure in the cohort. The exposures were reduced considerably after the first years of mining, when effective ventilation was introduced. In contrast to the situation in other countries, there was never extensive dry drilling in the Czechoslovak uranium mines, so that silicosis has not been a major problem. There were few (one to two) cases of silicosis per year, almost all of them in miners who had previously worked in nonuranium mines.

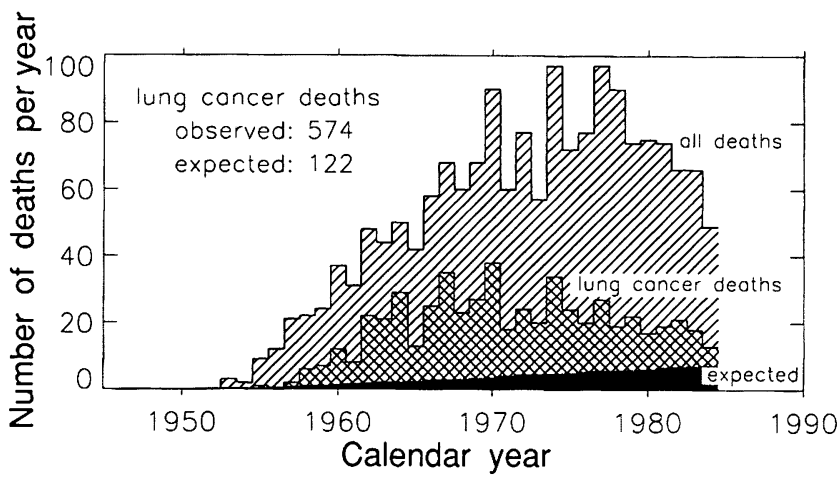

Fig. 1. Number of miners in the cohort (full line) and number of miners at work (broken line) in the specified calendar years.
Fig. 4 gives the number of lung cancer deaths in specified years and the total number of deaths. It is seen that, especially in the early years, lung cancer contributed a strikingly high fraction of all deaths. The lower,

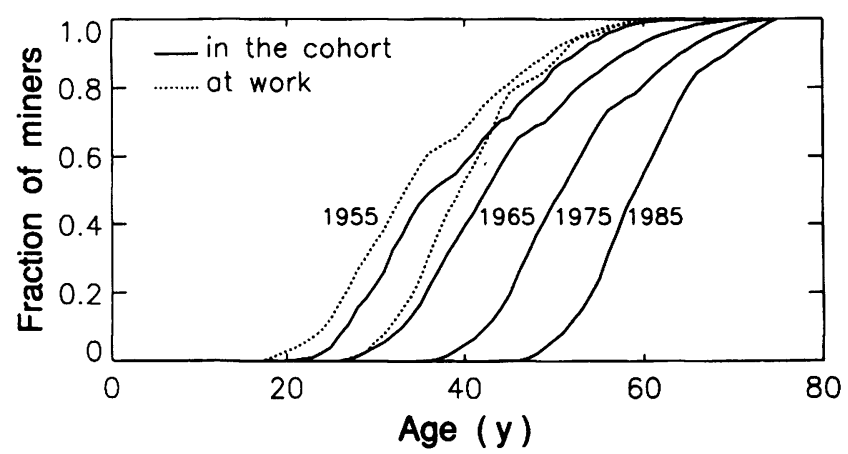

Fig. 2. Fraction of miners below the specified age in the given calendar years. The full lines refer, as in Fig. 1, to the cohort of miners at risk; the dotted lines refer to the miners at work in the year 1955 and 1965.

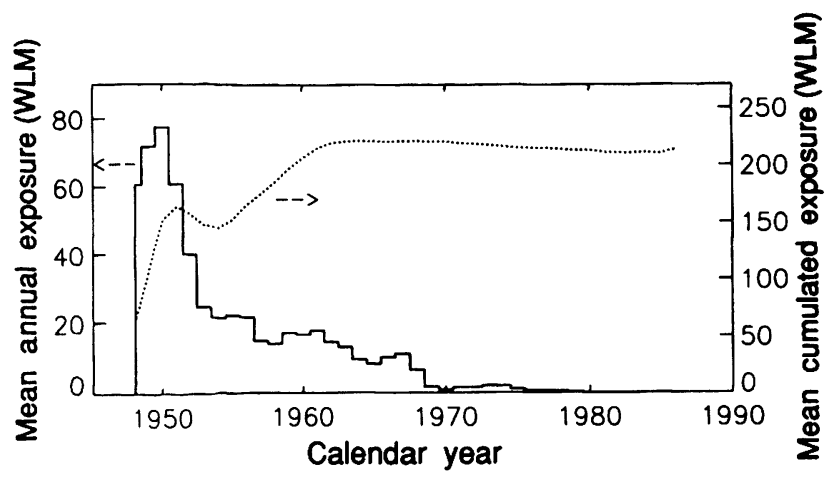

Fig. 3. Mean annual exposure received by the miners (full line) and mean cumulated exposure in the cohort (dotted line) vs. calendar years.

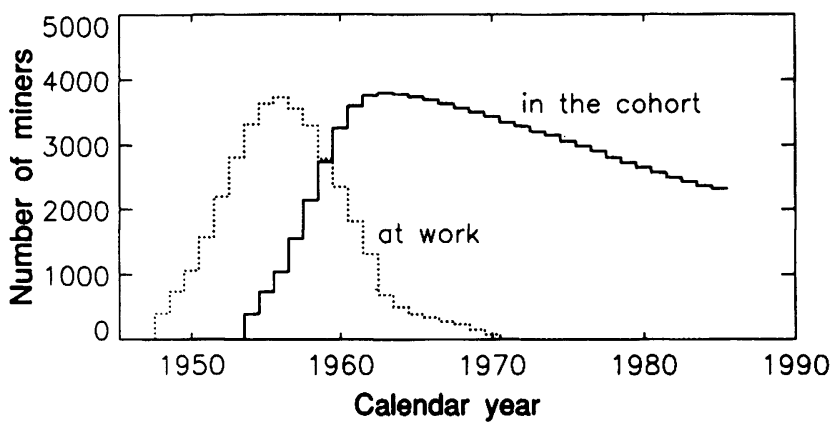

Fig. 4. Number of deaths in the specified calendar year. Upper line: observed number of deaths; intermediate line: observed number of lung cancer deaths; lower line: expected number of lung cancer deaths. 
dark band gives the number of lung cancer deaths that would have been expected in a normal male population of the same age distribution according to Czechoslovak national age-specific lung cancer mortality rates for the corresponding calendar years. The observed number of lung cancer deaths was 574; the expected number was 122. The mortality rates from all causes other than lung cancer were not significantly different from those expected on the basis of national statistics.

The national age-specific lung cancer mortality rates for males are represented in Fig. 5. Since there is no internal control group in the follow-up of the S-cohort, external data (i.e., age-specific rates from the national statistics from 1961-1985) were used in the analysis which is presented in the subsequent sections. No information on the smoking habits of the individual miners in the whole cohort is available. But, in a sample of 300 miners of the S-cohort, the fraction of smokers appeared to be about equal to the fraction of males smoking nationwide (Sevc et al. 1986; Kubík 1979). The miners belonged largely to a rural population, and although they were, on the average, paid better than other workers, there was no indication that they smoked more than males nationwide. There were no special provisions of cigarettes for miners, and cigarettes were readily available after 1948 in Czechoslovakia. After 1960 , the miners were forbidden to smoke during work.

\section{DIAGRAMS OF ESSENTIAL CHARACTERISTICS OF THE S-COHORT}

In this section, essential age-related information and data concerning the exposures, as well as the number of observed and expected lung cancers, will be given.

Fig. 6 represents the number of miners who started mining at the specified ages. The mean age at the beginning of work was $32.4 \mathrm{y}$. Among a total of 4,042 miners, 291 started mining at an age $<20$ y, and 38 started mining after they had reached age $55 \mathrm{y}$. Also included in the figure is the number of miners who terminated work at the specified age; the mean age was $40.6 \mathrm{y}$.

Fig. 7 gives the distribution in age of total personyears at work and of the total number of person-years under observation (4 y after start of mining being disregarded). The total number of person-years at work is 33,290 . The total number of person-years under observation is 97,913 , which corresponds to a mean time period at risk of $23.3 \mathrm{y}$ in the cohort. Also given in the figure is the collective exposure incurred at a specified age. In agreement with previous analyses, for example in BEIR IV (NRC 1988), a lag time period of $5 \mathrm{y}$ is used in the subsequent computations, i.e., exposures are integrated only up to 5 y before the specified age. The simple term "cumulated exposure" is used to refer to this lagged exposure when not otherwise specified.

Fig. 8 gives the collective cumulative exposure up

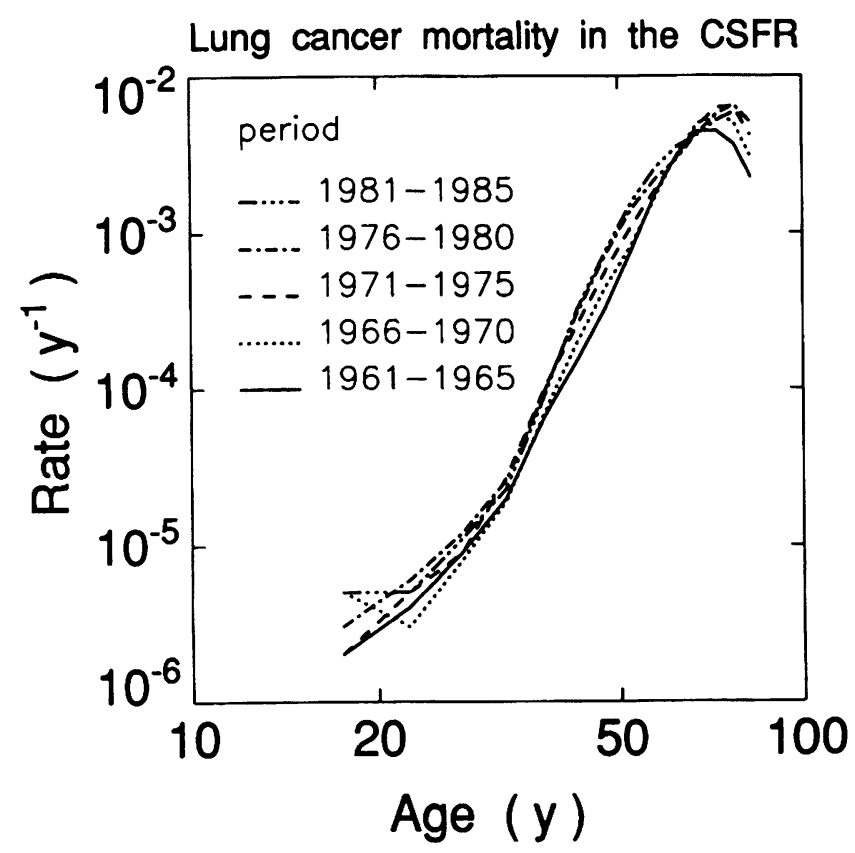

Fig. 5. Age-specific lung cancer mortality rates for the specified calendar periods in the CSFR.

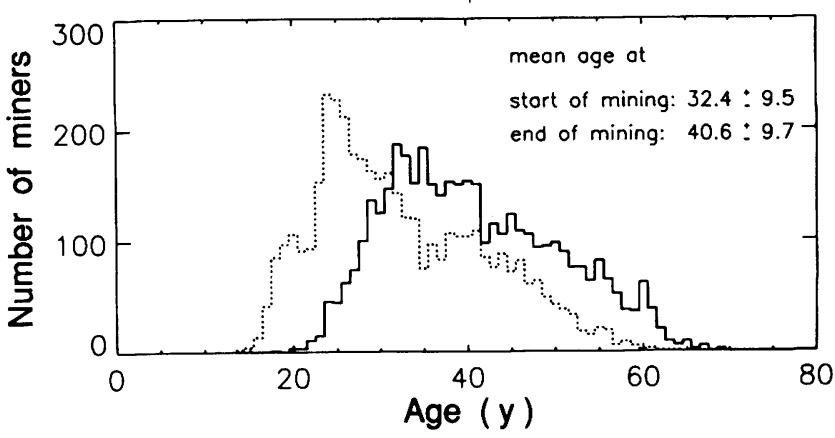

Fig. 6. Distribution of the number of miners in age at start of mining (dotted line) and at end of mining (full line). The means are given with the standard deviation.

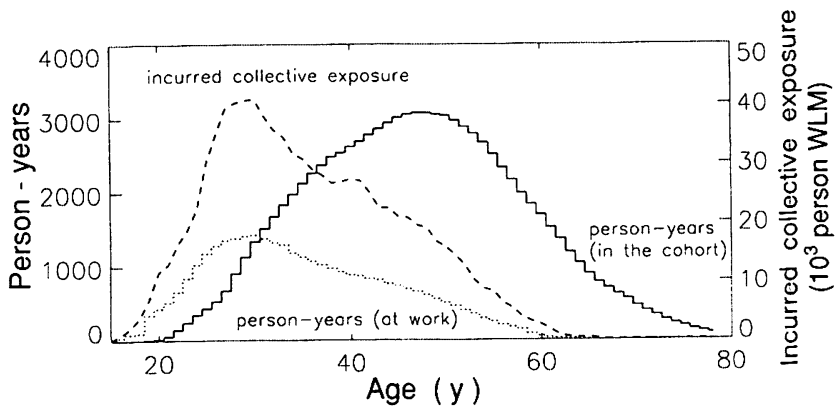

Fig. 7. Numbers of miners in the cohort (full line) or at work (dotted line) and incurred exposure (broken line) at the specified ages. Miners are counted in the cohort $4 \mathrm{y}$ after start of mining. 
to specified ages, the distribution of lung cancer deaths, and the distribution of expected cases by age.

Fig. 9 gives, averaged over all members of the cohort alive at the specified age, the mean cumulated exposures with no lag time period and with lag time periods of 5 and $10 \mathrm{y}$.

Fig. 10 gives the number of miners who were active for the specified durations. The mean duration of work was $8.2 \mathrm{y}$. As pointed out earlier, this excludes almost all who worked in the mines for $<4 \mathrm{y}$. The small number of 300 miners with more than $15 \mathrm{y}$ at work, and the fact that very few exceeded $20 \mathrm{y}$ at work, reflects regulations (passed in the early 1970s) that, by offering alternative employment, encouraged miners not to work more than $15 \mathrm{y}$ underground. The broken line gives, for the specified durations of work, the mean cumulated exposure of the miners.

Fig. 11 gives, in the upper panel, the distribution of miners in exposures cumulated at the end of their

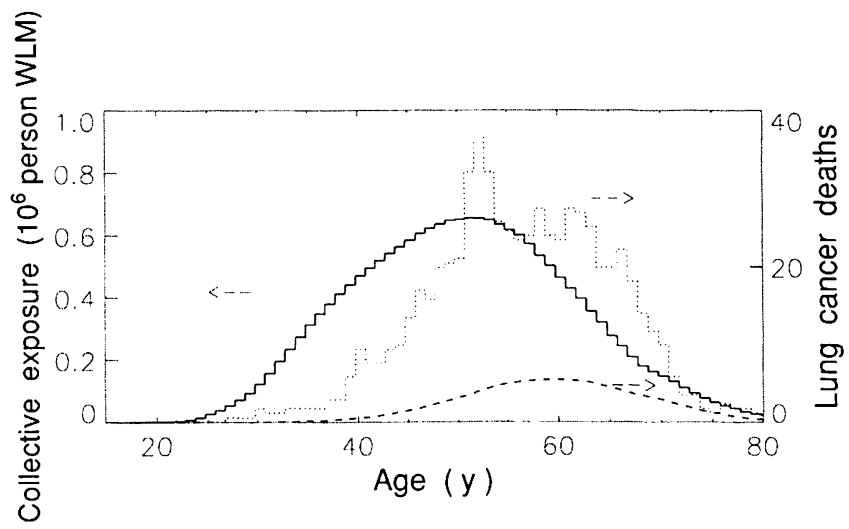

Fig. 8. Cumulated collective exposure of the miners in the cohort (full line) and observed number (dotted line) and expected number (broken line) of lung cancers deaths at the specified ages.

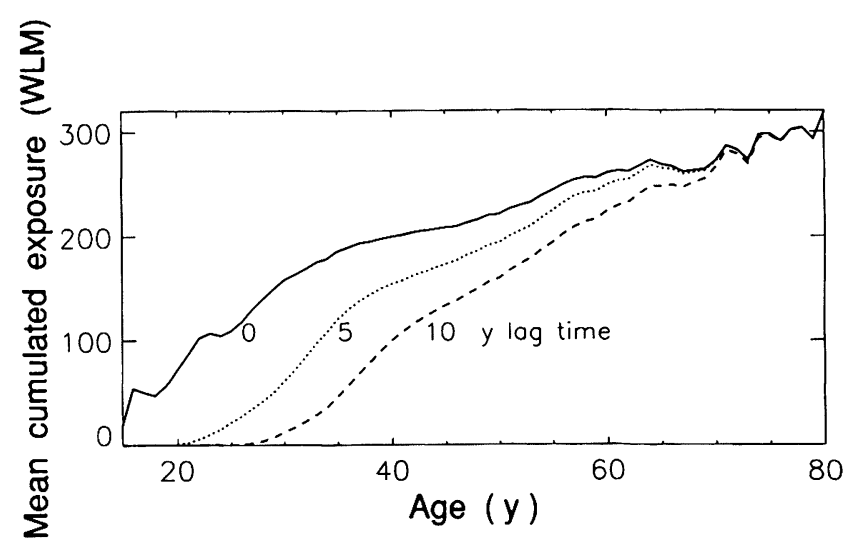

Fig. 9. Mean cumulated exposure of the miners at the specified ages. Full line: no lag time; dotted line: 5-y lag time; broken line: 10-y lag time. working time period, together with the mean age during the follow-up and the mean age at median exposure. In the lower panel, it gives the distribution of collective cumulated exposure in (individual) cumulated exposure at the end of the working time period and, for comparison, the distribution of lung cancer deaths.

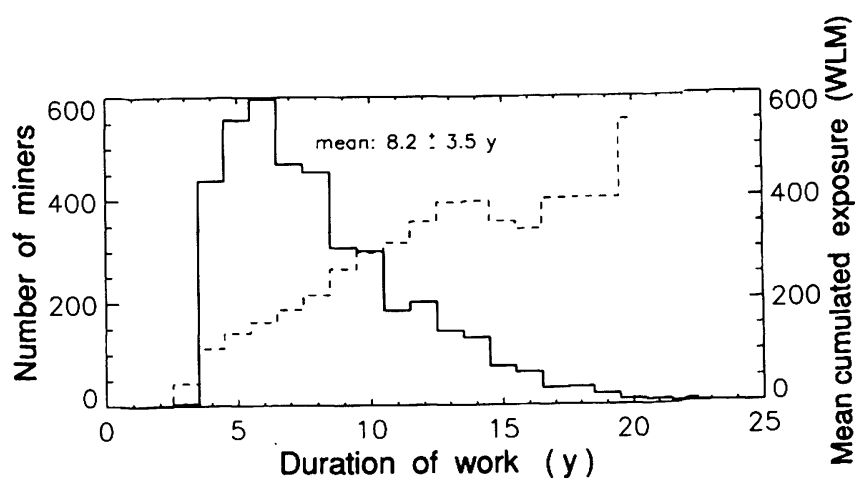

Fig. 10. Distribution of the number of miners in duration of work, i.e., time from beginning to end of mining (full line), and mean cumulated exposure of the miners with specified duration of mining (broken line). The mean duration of employment is given with the standard deviation.
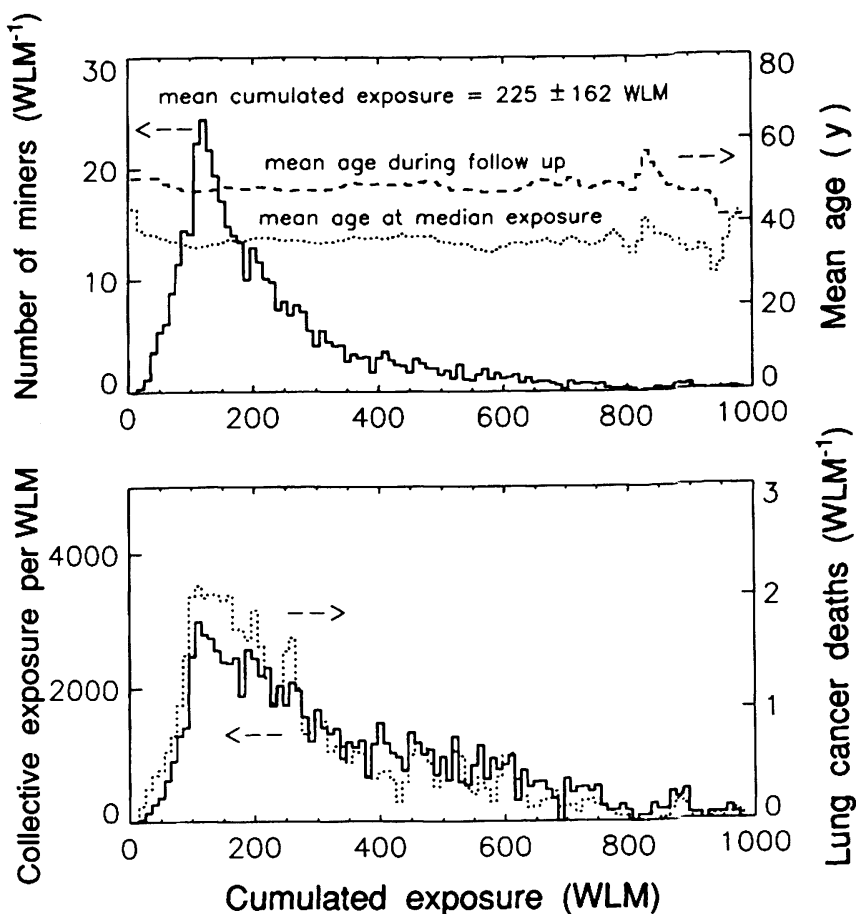

Fig. 11. Upper panel: distribution of number of miners, in total cumulated exposure (full line), mean age during the follow up (broken line), and mean age at median exposure (dotted line), vs. cumulated exposure. The mean cumulated exposure is given with its standard deviation. Lower panel: collective exposure (full line) and lung cancer deaths (dotted line) distributed in total cumulated exposure. 


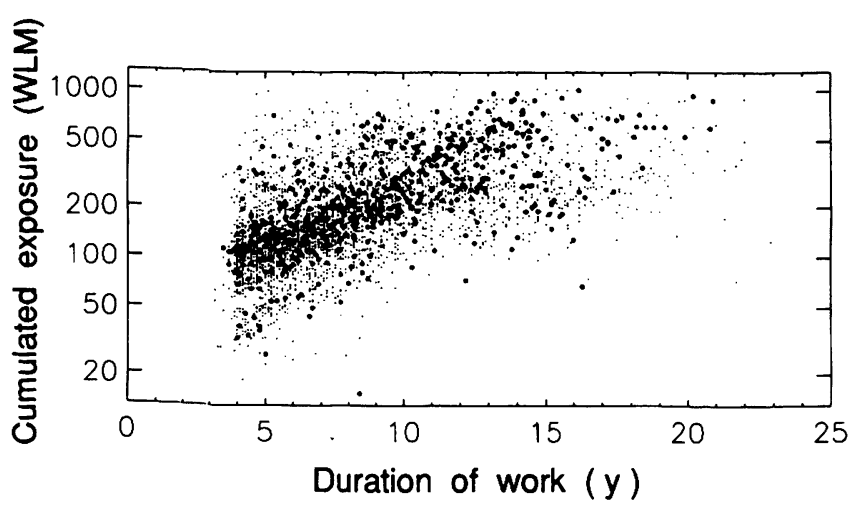

Fig. 12. Scatter diagram of duration of work and cumulated exposure. Each miner is represented by a dot; a miner who died from a lung cancer is represented by a heavy dot.

Fig. 12 brings together information that is partly contained in Figs. 9 and 10. It is a scatter diagram where each miner is represented by a point indicating that person's total duration of work and final cumulated exposure. The diagram indicates the correlation between work duration and cumulated exposure. While there is, as seen in Fig. 10, a clear correlation, it is also apparent that there is a broad variation of cumulated exposures for any specified duration of work. These variations largely reflect the sharp decline of exposure rates after the early years of uranium mining. The heavy dots represent miners who have died of lung cancer.

\section{NONPARAMETRIC ANALYSIS}

For a first, elementary analysis, the data are translated into two tables of numbers that are given in the appendix. Table 1A shows person-years-at-risk in cells ${ }^{\S \S}$ of age attained and of cumulated exposure (lagged by 5 $y)$. Table $2 \mathrm{~A}$ contains the numbers of deaths in the same cells of age attained and lagged cumulative exposure. The data in the tables go up to age 80 .

The most elementary estimate of the lung cancer mortality rate and its standard error are obtained in terms of the ratio $r_{i, k}$ of the number $n_{i, k}$ of lung cancer deaths and the number $p_{i, k}$ of person-years in the cell $(i, k)$ :

$$
r\left(a_{i}, C_{k}\right)=r_{i, k}=n_{i, k} / p_{i, k} \pm \sqrt{n_{i, k}} / p_{i, k}
$$

where $a_{i}$ and $C_{k}$ are the mean age attained and the mean cumulated exposure for the cell $(i, k)$.

The matrix of these numbers is given in Table 2 . Cells are left empty where there are no lung cancer deaths and $<50$ person-years at risk. The bottom row, corresponding to exposure zero, contains the age-specific spontaneous rates that are used in the subsequent calculations. They are based on the national rates (see Fig. 5) averaged over the time period 1960-1985. The standard mortality ratios (SMR) are equal to the numbers in the table divided by the corresponding numbers in the bottom row. The table is, of course, not very meaningful without the indication of standard errors, and it is also evident that the numbers are dependent on the somewhat arbitrary choice of cell sizes. However,

\footnotetext{
$\$$ A cell designates a range of cumulated exposures and ages. Such cells are used in the computations, since it is impractical in the numerical analysis to use the data in full detail. Hence, the data are categorized in cumulated exposure, attained age, and (where required) in other variables, such as time since exposure.
}

Table 2. Crude annual rates of lung cancer deaths per 10,000 persons distributed in age and in cumulated exposure (lagged by $5 \mathrm{y}$ ). The numbers are the ratios of the corresponding numbers in Tables $1 \mathrm{~A}$ and $2 \mathrm{~A}$. For the definition of the cells see Table 1A. The lowest line gives the age specific spontaneous rates calculated on the basis of national statistics, averaged over the calendar years 1961-1985. Dots represent cells with no cancer deaths and with less than 50 person-years.

\begin{tabular}{|c|c|c|c|c|c|c|c|c|c|c|c|c|c|c|c|c|c|c|c|c|c|}
\hline \multirow{2}{*}{$\begin{array}{c}\text { Exposure } \\
\text { (WLM) }\end{array}$} & \multicolumn{21}{|c|}{ Age $(y)$} \\
\hline & 29 & 32 & 34 & 37 & 39 & 42 & 44 & 47 & 49 & 52 & 54 & 57 & 59 & 62 & 64 & 67 & 69 & 72 & 74 & 77 & 79 \\
\hline 920 & & & & & & & & & & & 299 & & 0 & & & & & & & & \\
\hline 731 & . & & & & 0 & 274 & 87 & 0 & 126 & 360 & 12 & 0 & 222 & 0 & 200 & 357 & 351 & & & & \\
\hline 581 & & & 0 & 83 & 46 & 0 & 63 & 129 & 129 & 194 & 106 & 210 & 217 & 56 & 455 & 135 & 120 & & & & \\
\hline 461 & 0 & 0 & 0 & 61 & 34 & 44 & 142 & 153 & 129 & 72 & 66 & 175 & 108 & 183 & 82 & 244 & 0 & 132 & 143 & & \\
\hline 366 & 0 & 0 & 0 & 0 & 61 & 0 & 0 & 85 & 53 & 104 & 184 & 56 & 65 & 279 & 139 & 70 & 340 & 303 & 0 & & . \\
\hline 291 & 0 & 0 & 40 & 0 & 44 & 79 & 61 & 40 & 38 & 125 & 149 & 41 & 81 & 30 & 182 & 181 & 59 & 260 & 0 & & . \\
\hline 231 & 0 & 0 & 0 & 32 & 16 & 41 & 12 & 49 & 41 & 91 & 106 & 70 & 96 & 207 & 114 & 25 & 345 & 112 & 0 & & . \\
\hline 184 & 0 & 0 & 69 & 0 & 0 & 63 & 38 & 28 & 27 & 107 & 86 & 76 & 99 & 160 & 154 & 84 & 147 & 145 & 148 & 0 & \\
\hline 146 & 0 & 49 & 16 & 0 & 11 & 0 & 17 & 37 & 54 & 63 & 98 & 90 & 168 & 133 & 115 & 288 & 164 & 0 & 0 & 0 & 0 \\
\hline 116 & 0 & 0 & 0 & 0 & 9 & 0 & 7 & 52 & 35 & 52 & 54 & 40 & 66 & 121 & 88 & 187 & 101 & 134 & 70 & 392 & . \\
\hline 9 & 0 & 0 & 0 & 0 & 24 & 0 & 49 & 36 & 36 & 56 & 0 & 46 & 95 & 39 & 131 & 216 & 70 & 0 & 0 & & . \\
\hline 73 & 0 & 35 & 0 & 0 & 0 & 0 & 23 & 31 & 65 & 101 & 113 & 41 & 35 & 60 & 0 & 96 & 167 & 0 & 0 & & . \\
\hline 58 & 0 & 0 & 0 & 0 & 0 & 49 & 0 & 0 & 34 & 0 & 41 & 149 & 0 & 0 & 99 & . & 303 & . & . & . & . \\
\hline 46 & 0 & 0 & 0 & 0 & 0 & 0 & 0 & 0 & 46 & 0 & 0 & 100 & 83 & 282 & 0 & . & . & & . & & . \\
\hline 37 & 63 & 0 & 0 & 0 & 57 & 0 & 0 & 0 & 71 & 0 & 0 & 139 & 0 & . & 175 & . & . & & . & & . \\
\hline 29 & 0 & 0 & 0 & 0 & 0 & 0 & 0 & & 0 & . & 0 & . & . & . & • & - & . & . & . & . & . \\
\hline 23 & 0 & 0 & 0 & 0 & 0 & . & 0 & 0 & 0 & . & . & . & . & . & . & . & . & . & . & & . \\
\hline 18 & 0 & 0 & 0 & 0 & 0 & . & 0 & . & . & & & . & . & . & . & . & & & . & & . \\
\hline 15 & 0 & 0 & 0 & . & . & & & & & 476 & & & & & & & 5,000 & & & & \\
\hline 0 & 0 & 0 & 0 & 1 & 1 & 2 & 3 & 5 & 7 & 10 & 14 & 18 & 23 & 29 & 35 & 42 & 48 & 53 & 55 & 56 & 56 \\
\hline
\end{tabular}


in the subsequent analysis, methods will be used that are less dependent on cell size.

Excess rates $r_{e}\left(a_{i}\right)$ are calculated on the basis of the two tables in the appendix by combining all cells of cumulative exposure for a specified age attained:

$$
r_{e}\left(a_{i}\right)=\sum_{k} n_{i, k} / \sum_{k} p_{i, k}-r_{o}\left(a_{i}\right),
$$

where $r_{o}(a)$ is the age-specific spontaneous rate. The results are given as the solid line in the upper panel of Fig. 13. Dividing $r_{e}(a)$ by the mean cumulated exposure at the specified age attained (each individual cumulated exposure is weighted by the time at risk in the age interval), the excess rate per 100 WLM (broken line) is obtained and recorded in the upper panel of Fig. 13. The dotted line gives, for comparison, the age-specific

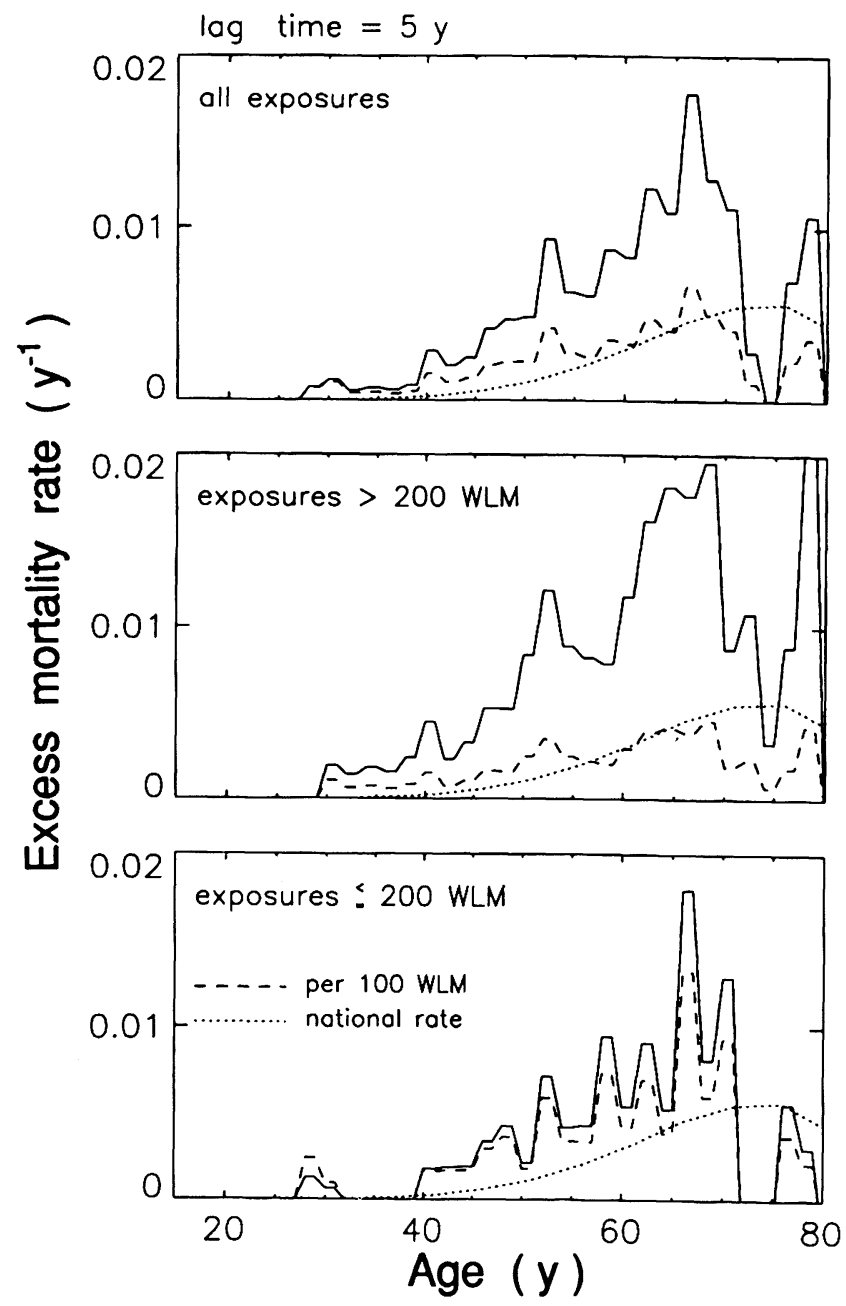

Fig. 13. Mean excess rates (full lines) and mean excess rates per 100 WLM (broken lines) for the miners in the cohort at the specified age (upper panel: all miners; intermediate panel: miners with total cumulated exposure $>200$ WLM; lower panel: miners with total cumulated exposure $\leq 200$ WLM). The dotted line gives, according to the national statistics averaged over 25 calendar years, the age-specific lung cancer mortality rates. spontaneous lung cancer mortality rate. The observed excess rate in the whole cohort is, up to age $70 \mathrm{y}$, about 2 to 3 times larger than the age-specific spontaneous rate; at younger ages, the ratio appears to be even higher. The mean excess rate per 100 WLM exceeds the spontaneous rate at ages up to about $65 \mathrm{y}$. At higher ages, the observed excess lung cancer rates are substantially lower. The reason is uncertain, but it may be connected to the higher longevity of nonsmokers, i.e., their increasing proportion in the cohort at higher ages. Insufficient reporting is not a likely reason because medical surveillance among the ex-miners was, on the average, better than among males nationwide.

The broken line in the upper panel in Fig. 13 is based on assumed proportionality between excess rate and cumulative exposure. To judge the validity of this as-

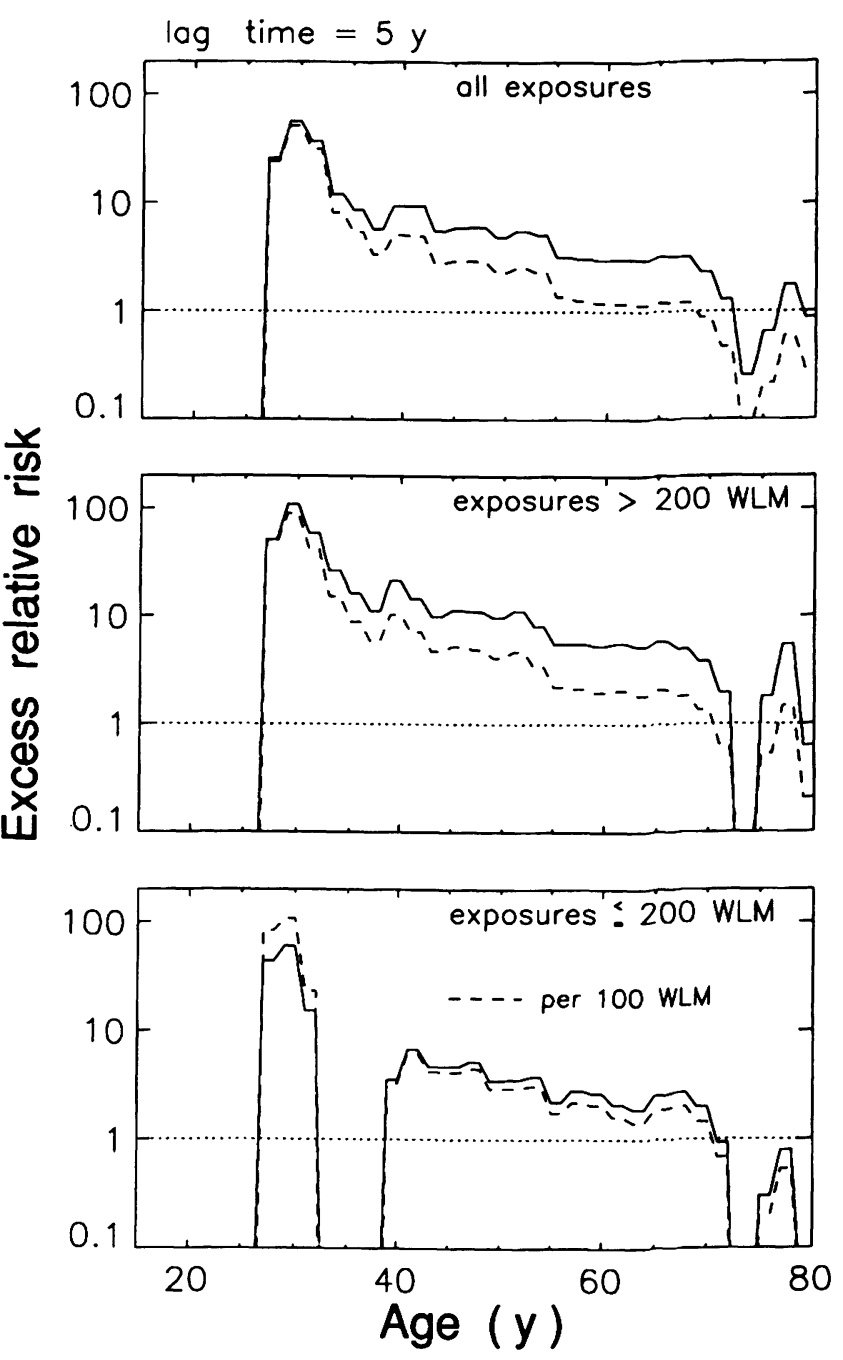

Fig. 14. Mean excess relative risk (full lines) and mean excess relative risk per 100 WLM (broken lines) for the miners in the cohort at the specified age (upper panel: all miners in the cohort; intermediate panel: miners with total cumulated exposure $>200$ WLM; lower panel: miners with total cumulated exposure $\leq 200 \mathrm{WLM}$ ). 
sumption, the analysis is also performed separately for all person-years at risk with cumulative exposures $>200$ WLM (intermediate diagram) and all person-years with cumulated exposures <200 WLM (bottom panel). While the absolute excess rates are, of course, higher for those with higher cumulated exposure, the mean excess rates per 100 WLM are larger for those with lower cumulated exposure. The difference suggests a nonlinear dependence of the excess rate on cumulated exposure, i.e., higher excess rates per WLM at lower cumulative exposure. This will be examined in a later section in this paper dealing with parametric regression.

Fig. 14 translates the information from Fig. 13 into relative excess rates, i.e., into the ratio of observed excess lung cancer mortality rate at the specified age to the age-specific national rate. The statistics are evidently poor at ages below $40 \mathrm{y}$ and above $70 \mathrm{y}$. In the intermediate range, however, it is possible to see a clear indication of substantial relative excess risks at the younger ages. At cumulated exposures of only 100 WLM, the relative excess rate appears to be substantially larger than 2 in the age range from 35 y to $55 \mathrm{y}$, suggesting a doubling of lung cancer rates at exposures $\leq 50 \mathrm{WLM}$. The dependences resemble an exponential decay of the relative excess risk with age attained, and this will be subsequently used in an analytical fit of the data in terms of relative risk models.

\section{ISOTONIC REGRESSION}

The matrix of elementary estimates in Table 2 can be seen as a representation of the lung cancer mortality rates $r(a, C)$ in their dependence on age attained, $a$, and cumulated exposure, $C$. If the numerical values were not subject to large statistical fluctuations, simple interpolation could be used to construct lines of equal values $r(a, C)$ in the plane of the two variables $a$ and $C$. The statistical variations of the matrix elements make this impracticable, but there is a numerical method, named isotonic regression, that estimates a matrix of values with substantially reduced fluctuations. This technique of isotonic regression (Barlow et al. 1972) uses the assumption that the true function $r(a, C)$ is monotonic in the variables $a$ and $C$, and it determines those matrix elements that are, with this constraint, closest to the observed values. The algorithm for isotonic regression over two variables is not trivial; we have used a computer code developed by Gebhard (1970).

A limitation of the data is the absence of an internal control group or of a large number of miners with low exposures. This makes estimates at low exposures uncertain. In the absence of a control group, the population rates for Czechoslovakia were used for the present analysis. This is, of course, somewhat hypothetical because it assumes the same smoking habits for the miners and the male Czechoslovak population during the time period of interest. There was, however, as stated, no indication that smoking habits were substantially different (Kubik 1979; Sevc et al. 1986). Utilizing the national rates means, in terms of the numerical analysis, inserting (at zero exposure) additional lines into the tables with large numbers of deaths and person-years, the ratio of which corresponds to the national agespecific rates; this forces all estimates in the isotonic regression to be at least equal to the national rates. Table 3 gives the tabular result of the isotonic regression, i.e., for each cell, the rate estimated with the isotonic regression. Fig. 15 gives the lines of equal rates that are obtained by interpolation from this table.

The isotonic regression has the advantage of a fairly transparent relation to the input data. It has the disadvantage that there is no ready method to give error intervals for the estimates. To provide at least a feeling for the degree of uncertainty of the estimates, the underlying lung cancer deaths are indicated by dots in the diagram. Estimates can be reliable only if there is a number of cancer deaths below the specified age and cumulated exposure. In spite of their limitations, the isotonic diagrams are a ready indication of the trend of increased lung cancer rates at increasing attained age and increasing cumulated exposures.

A somewhat more tangible diagram can be given in terms of relative rates, i.e., rates that are scaled to the age-specific normal rates at the specified attained age. These relative rates are given in Fig. 16. They are not, as can be seen, monotonous in cumulated exposure and age attained. The figure shows, however, a general trend of increasing relative rates for decreasing age attained and increasing cumulated exposure. The isotonic regression could, therefore, be based on the somewhat more stringent constraint that the relative rates increase with increasing cumulated exposure and decreasing age attained. However, the results of such an analysis are not presented here since the isotonic regression serves only as a rough indicator of the dependence of the rates on cumulated exposure and age attained.

The data from Fig. 15 are redrawn, in the two panels of Fig. 17, to indicate the nature of the dose and age relations that can be invoked in analytical fits. In the top panel, the rates are given in their dependence on cumulated exposure for specified attained ages. The curves indicate, at low cumulated exposures, a supralinearity of the dose relation that is particularly marked at the higher attained ages. In the bottom panel, the rates are given as a function of attained age for specified cumulated exposures. Note that the lung cancer mortality rates are roughly doubled at 50 WLM.

\section{PARAMETRIC REGRESSION}

The nonparametric analysis in terms of isotonic regression is a suitable method to indicate the general trend of the dependence of lung cancer mortality rate on cumulated exposure and age. It is, however, difficult 
Table 3. The analogue to Table 2 with rates that are obtained from isotonic regression, i.e., rates that fit the observations best under the condition of increasing monotonicity with age and with cumulated exposure.

\begin{tabular}{|c|c|c|c|c|c|c|c|c|c|c|c|c|c|c|c|c|c|c|c|c|c|}
\hline \multirow{2}{*}{$\begin{array}{c}\text { Exposure } \\
\text { (WLM) }\end{array}$} & \multicolumn{21}{|c|}{ Age (y) } \\
\hline & 29 & 32 & 34 & 37 & 39 & 42 & 44 & 47 & 49 & 52 & 54 & 57 & 59 & 62 & 64 & 67 & 69 & 72 & 74 & 77 & 79 \\
\hline 920 & 2 & 44 & 44 & 44 & 111 & 111 & 111 & 111 & 163 & 163 & 163 & 182 & 182 & 242 & 242 & 242 & 242 & 242 & 242 & 2422 & 242 \\
\hline 731 & 2 & 44 & 44 & 44 & 44 & 111 & 111 & 111 & 128 & 128 & 128 & 163 & 182 & 182 & 242 & 242 & 242 & 242 & 242 & & \\
\hline 581 & 2 & 44 & 44 & 44 & 44 & 44 & 104 & 111 & 111 & 111 & 111 & 163 & 163 & 163 & 242 & 242 & 242 & 242 & 242 & & 2 \\
\hline 461 & 2 & 9 & 15 & 41 & 44 & 44 & 104 & 104 & 104 & 110 & 110 & 137 & 137 & 163 & 163 & 174 & 174 & 174 & 174 & 174 & 4 \\
\hline 366 & 2 & 9 & 15 & 15 & 44 & 44 & 44 & 66 & 66 & 110 & 110 & 110 & 110 & 163 & 163 & 163 & 174 & 174 & 174 & 174 & 4 \\
\hline 291 & 2 & 9 & 15 & 15 & 44 & 44 & 44 & 44 & 44 & 110 & 110 & 110 & 110 & 136 & 163 & 163 & 163 & 163 & 163 & 1631 & 163 \\
\hline 231 & 2 & 9 & 15 & 15 & 16 & 16 & 36 & 42 & 42 & 92 & 92 & 92 & 110 & 136 & 136 & 163 & 163 & 163 & 163 & 163 & 163 \\
\hline 184 & 2 & 9 & 15 & 15 & 15 & 15 & 36 & 40 & 41 & 92 & 92 & 92 & 110 & 136 & 136 & 136 & 141 & 141 & 141 & 141 & 141 \\
\hline 146 & 2 & 9 & 9 & 9 & 9 & 9 & 21 & 40 & 41 & 63 & 63 & 63 & 110 & 110 & 110 & 136 & 136 & 136 & 136 & & 13 \\
\hline 116 & 2 & 2 & 2 & 2 & 9 & 9 & 21 & 40 & 40 & 52 & 52 & 52 & 77 & 106 & 106 & 129 & 129 & 129 & 129 & 129 & 129 \\
\hline 92 & 2 & 2 & 2 & 2 & 9 & 9 & 21 & 36 & 40 & 52 & 52 & 52 & 77 & 83 & 106 & 106 & 106 & 106 & 106 & 10 & 106 \\
\hline 73 & 2 & 2 & 2 & 2 & 6 & 9 & 21 & 21 & 40 & 40 & 52 & 52 & 52 & 83 & 83 & 106 & 106 & 106 & 106 & 106 & 106 \\
\hline 58 & 2 & 2 & 2 & 2 & 6 & 9 & 9 & 18 & 27 & 27 & 41 & 52 & 52 & 83 & 83 & 106 & 106 & 106 & 106 & 106 & 106 \\
\hline 46 & 2 & 2 & 2 & 2 & 6 & 6 & 6 & 18 & 27 & 27 & 27 & 52 & 52 & 83 & 83 & 106 & 106 & 106 & 106 & 1061 & 106 \\
\hline 37 & 2 & 2 & 2 & 2 & 2 & 2 & 6 & 18 & 27 & 27 & 27 & 52 & 52 & 52 & 83 & 106 & 106 & 106 & 106 & 1061 & 106 \\
\hline 29 & 0 & 0 & 0 & 1 & 1 & 2 & 3 & 18 & 18 & 27 & 27 & 27 & 27 & 29 & 83 & 83 & 106 & 106 & 106 & 1061 & 106 \\
\hline 23 & 0 & 0 & 0 & 1 & 1 & 2 & 3 & 5 & 7 & 27 & 27 & 27 & 27 & 29 & 35 & 42 & 106 & 106 & 106 & 1061 & 106 \\
\hline 18 & 0 & 0 & 0 & 1 & 1 & 2 & 3 & 5 & 7 & 27 & 27 & 27 & 27 & 29 & 35 & 42 & 106 & 106 & 106 & 1061 & 106 \\
\hline 15 & 0 & 0 & 0 & 1 & 1 & 2 & 3 & 5 & 7 & 27 & 27 & 27 & 27 & 29 & 3. & 42 & 106 & 106 & 106 & 1061 & 106 \\
\hline 0 & 0 & 0 & 0 & 1 & 1 & 2 & 3 & 5 & 7 & 27 & 27 & 27 & 27 & 29 & 35 & 42 & 48 & 53 & 55 & 56 & 56 \\
\hline
\end{tabular}

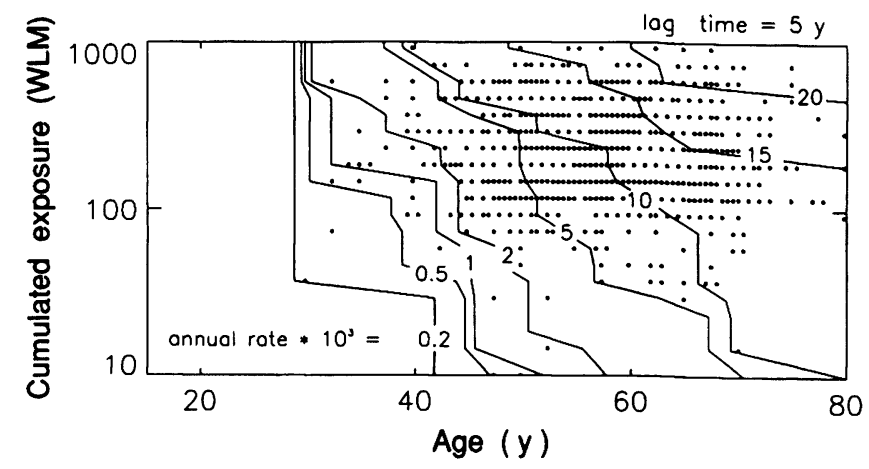

Fig. 15. Lines of constant rates of lung cancer death in age and cumulated exposure. The results are obtained by isotonic regression. The dots indicate lung cancer deaths at the specified attained age and cumulated exposure.

with isotonic regression to discriminate valid features of the results from those that may be artifacts of statistical uncertainty, and it is impossible to account for added factors that may influence the lung cancer rates. Parametric regression must, therefore, be used to assess the influence of the different variables that have been considered in BEIR IV (NRC 1988), namely-next to exposure and age attained-time since exposure and duration of exposure.

However, a somewhat broader treatment is required for several reasons. The BEIR IV model (NRC 1988) contains step functions, for example, in the dependence of the excess rates on age attained. The use of step functions is unsatisfactory, especially with regard to the derivation of probabilities of causation. In the earlier treatment such functions were nevertheless used

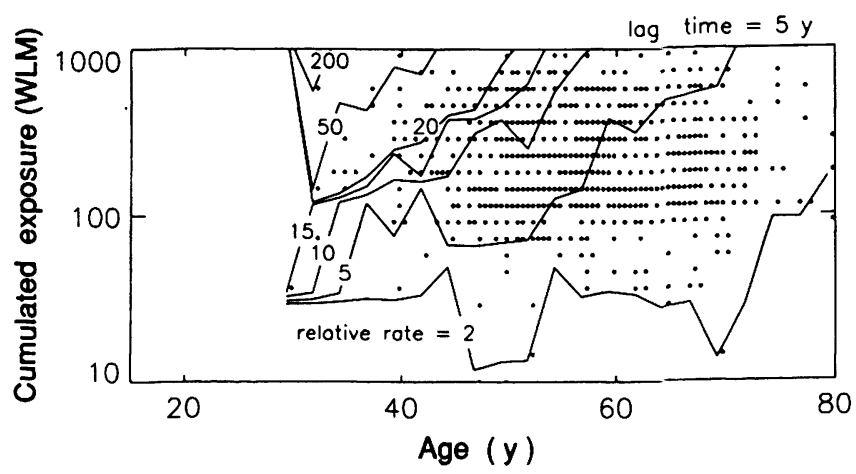

Fig. 16. Lines of constant relative lung cancer mortality rate in age and cumulated exposure. The rates from the isotonic regression have, for this diagram, been divided by the spontaneous rates at the specified ages (see text). The dots indicate lung cancer deaths at the specified attained age and cumulated exposure.

to avoid the potential bias of an arbitrarily chosen model. In the present study, it is possible to choose, on the basis of the results of the isotonic regression, suitable analytical expressions. This permits the use of equations that can also, at least approximately, account for a nonlinear dependence on cumulated exposure.

The program package EPICURE, for general use in epidemiological risk computations, has been used for the parametric regression. It contains, among other parts, the algorithm AMFIT to derive maximum likelihood solutions for various relative risk models. The data were categorized in attained age, in cumulated exposure (with a lag time period of $5 \mathrm{y}$ ) at the attained age, and in certain other variables, as will be pointed 
out subsequently. The regression is based on Poisson statistics, i.e., the likelihood is computed on the basis of the observed number of deaths and the expectations according to the model parameters in each cell. It is assumed that the variation of the variables of interest, e.g., spontaneous rate, cumulated exposure, or age attained, have, inside a cell, little influence on the lung cancer rates. The procedure would, apart from the grouping of the data, correspond to the Cox proportional hazards model if the spontaneous age-specific rates were estimated from the data. However, as stated, the national age-specific rates have been used in the present analysis.

Tables of person-years at risk and of the number of cases were generated with the subroutine DATAB which is also part of EPICURE. These tables are identical to Tables $1 \mathrm{~A}$ and $2 \mathrm{~A}$ when only age attained and cumulated exposure are considered. The same subdivision in attained age and cumulated exposure was used to ensure comparability of the results from the nonparametric and the parametric analyses. Added computations with different cell sizes were used to ascertain that the results are not substantially dependent on the choice of cell size. The actual results were obtained with inclusion of two more variables, i.e., age at median exposure (categorized into eight classes) and duration of exposure (categorized into four classes).

\section{The BEIR IV approach}

For a first, direct comparison with earlier work (NRC 1988; Lubin 1988; Lubin and Gaffey 1988), the same type of model was chosen that had also been used by the BEIR IV Committee, i.e., the following expression:

$$
r(a, C)=r_{o}(a)\left[1+g(a) \sum_{i=1}^{3} b_{i} C_{i}\right]\left(\text { with } b_{1}=1\right),
$$

with the following parameters suggested by the BEIR IV Committee on the basis of their pooled analysis:

$$
\begin{aligned}
\gamma_{1} & =0.03 & & \text { for } a<55 \\
g(a)= & \gamma_{1}=0.025 & & \text { for } 55 \leq a \leq 64 \\
\gamma_{2} & =0.01 & & \text { for } 64<a .
\end{aligned}
$$

$C_{1}, C_{2}$, and $C_{3}$ are the exposures cumulated in three intervals prior to the attained age, $a$, in years. If $t$ is the time since exposure in years, $C_{1}, C_{2}$, and $C_{3}$ refer to the time intervals $(5<t<15),(15 \leq t \leq 25)$, and $(25<t)$, respectively. The BEIR IV Committee concluded from its analysis that two components $C_{i}$ allowed an adequate description; i.e., they have used the values $b_{2}=b_{3}=0.5$. The present data suggest the need for three intervals. The numerical results are given in Table 4.

The calculations with this model require a threefold classification in cumulated exposure at each age attained. The relatively fine subdivision into cells is, therefore, impracticable. Instead, a subdivision with broad intervals in age attained and cumulated exposure
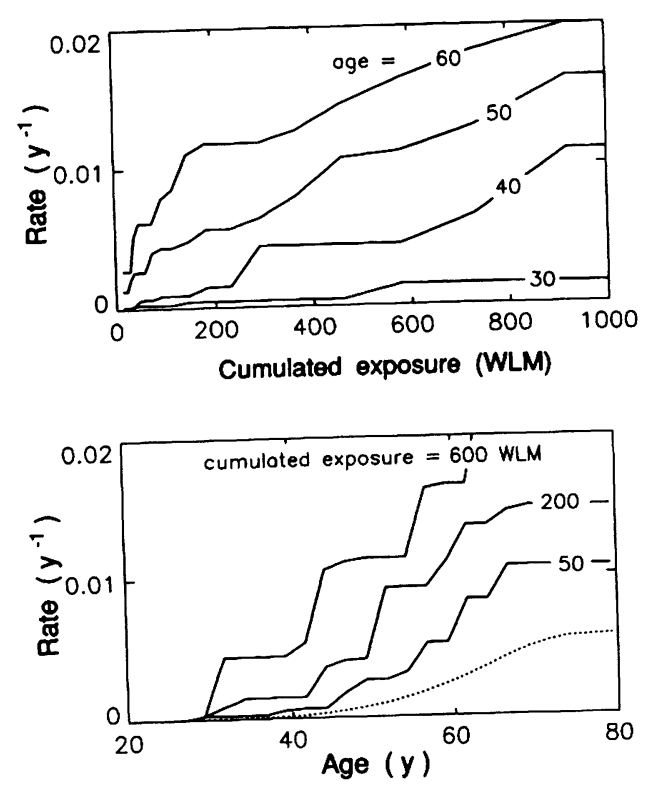

Fig. 17. Different presentation of the data from Fig. 15 (upper panel: rates vs. cumulated exposure for the specified attained ages; lower panel: rates vs. attained age for the specified cumulated exposures). The dotted line indicates the spontaneous age-specific rate.

Table 4. Results of the maximum likelihood fits to the data of the S-cohort in terms of a model that corresponds to the approach of BEIR IV (see eqn 3). Model 1.1 disregards the dependence on time since exposure, model 1.2 equates the parameters $b_{2}$ and $b_{3}$. The lowest line gives, for comparison, the parameter values that were derived by the BEIR IV Committee in the pooled analyses of their data. $r(a, C)=$ $\mathrm{r}_{0}(\mathrm{a})\left(1+\mathrm{g}(\mathrm{a}) \times \sum_{i} b_{i} C_{i}\right), i=1$ to $3 ; \mathrm{b}_{1}=1$; the estimates of the parameters are given with their standard error. The units year and WLM are used.

\begin{tabular}{cccrrrr}
\hline Model & $\mathrm{b}_{2}$ & $\mathrm{~b}_{3}$ & \multicolumn{1}{c}{$\gamma_{1}$} & \multicolumn{1}{c}{$\gamma_{2}$} & \multicolumn{1}{c}{$\gamma_{3}$} & $\operatorname{Dev}(\mathrm{df})^{\mathrm{a}}$ \\
\hline 1.1 & 1 & & 0.0377 & 0.0141 & 0.0076 & 586.8 \\
& & \pm 0.0027 & \pm 0.0013 & \pm 0.0012 & $(130)$ \\
1.2 & 0.356 & 0.0616 & 0.0275 & 0.0183 & 534.1 \\
& \pm 0.049 & \pm 0.0054 & \pm 0.0030 & \pm 0.0032 & $(129)$ \\
1.3 & 0.677 & 0.099 & 0.053 & 0.026 & 0.018 & 496.6 \\
& \pm 0.100 & \pm 0.047 & \pm 0.005 & \pm 0.003 & \pm 0.003 & $(128)$ \\
BEIR IV & 0.5 & 0.03 & 0.025 & 0.01 & - \\
\hline
\end{tabular}

${ }^{\mathrm{a}}$ Dev $=$ deviance; $\mathrm{df}=$ number of degrees of freedom.

was adapted that is similar to the one used by the BEIR IV Committee. The results of these computations are given in Table 4 and are illustrated in Fig. 19. The maximum likelihood solution gives higher relative excess risks for lower attained ages than the BEIR IV analysis, but lower values for higher attained ages. To enable the reader to judge the improvement due to the introduction of additional parameters, Table 4 and 
Table 6 contain, for each model, the value of likelihood and the number of degrees of freedom.

To illustrate the results and compare them to solutions for other models in the subsequent section, it is possible to consider a uniform exposure from age $25 \mathrm{y}$ to $35 \mathrm{y}$, subsequently called the reference exposure. Table 5 gives the excess relative risk for lung cancer mortality for the present data and eqn (3), and compares these values to those derived by the BEIR IV Committee for their major cohorts. It also contains the values that are obtained with different models, as explained in the following sections.

\section{A more general treatment}

The approach taken by the BEIR IV Committee cannot account for a possible nonlinearity of the dependence on exposure. However nonlinearity is suggested by the data (see Figs. 13, 14, and 17). An analytical model was used that postulates a dependence of

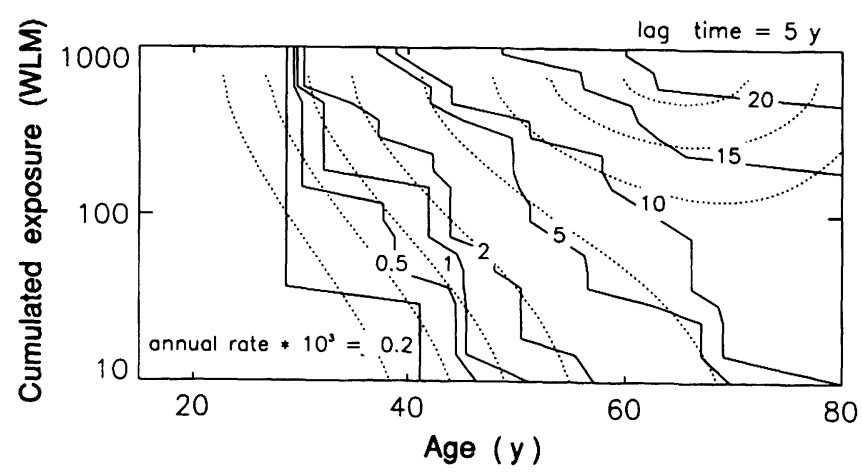

Fig. 18. Lines of constant lung cancer mortality rate in cumulated exposure and attained age. Full lines: rates obtained with isotonic regression (see Fig. 15); dotted lines: rates obtained with a fit to the linear-quadratic expression (Model 1.3 in Table 6).

Table 5. Excess relative risks at specified attained ages and for an assumed uniform exposure between ages 25 and 35 to 100 WLM. The values predicted by the BEIR IV Committee are compared to values derived in the present analysis for the Scohort in terms of three different models. At 200 WLM the three models would lead to nearly the same results. The analysis of the S-cohort suggests excess relative risks that are somewhat larger than in the analyses of BEIR IV at young ages and somewhat smaller at old ages.

\begin{tabular}{ccccc}
\hline Age & BEIR IV & $\begin{array}{c}\text { Model 1.3 in } \\
\text { Table 4 }\end{array}$ & $\begin{array}{c}\text { Model 1.7 } \\
\text { in Table 6 }\end{array}$ & $\begin{array}{c}\text { Model 2.2 in } \\
\text { Table 6 }\end{array}$ \\
\hline 40 & 3.00 & 5.30 & 8.68 & 10.6 \\
45 & 2.25 & 4.45 & 5.13 & 6.47 \\
50 & 1.50 & 3.59 & 3.04 & 3.95 \\
55 & 1.25 & 1.01 & 1.80 & 2.41 \\
60 & 1.25 & 0.26 & 1.06 & 1.47 \\
65 & 0.50 & 0.18 & 0.63 & 0.89 \\
70 & 0.50 & 0.18 & 0.37 & 0.54 \\
75 & 0.50 & 0.18 & 0.22 & 0.33 \\
\hline
\end{tabular}

the proportional hazard factors on a linear-quadratic expression in cumulated exposure, $C$, while the dependences, $g(a)$, on age attained and, $b(t)$, on time since exposure are represented by exponential terms $e^{-\gamma a}$ and $e^{-\mu \eta}$ :

$$
r(a, C)=r_{o}(a)\left(1+\left(\alpha C-\beta C^{2}\right) e^{-\gamma a} e^{-\mu \eta}\right) .
$$

In this equation, $e^{-\mu \eta}$ accounts for the reduction of the relative risk with time since exposure. In principle, this would have to involve a summation [as in eqn (3)] or an integration over the temporal distribution of exposure. However, for reasons of calculation practicability in the program AMFIT, this is approximated by the parameter $\eta$ which depends on the time since median exposure. If $a$ is the age attained and $a_{m}$ is the age when one-half of the ultimate exposure was reached, the parameter $\eta$ is set equal to the time since median exposure $>10 \mathrm{y}$ :

$$
\eta=\begin{array}{cl}
0 & \text { for } a-a_{m} \leq 10 \mathrm{y} \\
a-a_{m}-10 \mathrm{y} & \text { for } a-a_{m}>10 \mathrm{y} .
\end{array}
$$

Table 6 gives the maximum likelihood solutions for this model and for its reduced forms that omit some of the parameters. Corresponding values of the excess relative risk are given in Table 5 . The simplest linear model accounts only for the parameter $\alpha$ (Model 1.1). The fit is greatly improved by allowing for a dependence on age attained (Model 1.2). A further improvement of the fit is obtained by including the negative quadratic

Table 6. Results of the maximum likelihood fits of the data from the S-cohort to eqns 4 and 6 . Where reduced forms of the model are used, the disregarded parameters are indicated by a dash. The decreasing values of the deviance indicate the improvement of the fit, as added parameters are introduced. The estimates of the parameters are given with their standard

\begin{tabular}{|c|c|c|c|c|c|c|}
\hline \multicolumn{7}{|c|}{$\mathrm{r}(\mathrm{a}, \mathrm{C})=\mathrm{r}_{0}(\mathrm{a})\left(1+\left(\alpha \mathrm{C}-\beta \mathrm{C}^{2}\right) \mathrm{e}^{-\gamma \mathrm{a}-\mu \eta}\right)$} \\
\hline Model & $\alpha$ & & $\beta$ & $\gamma$ & $\mu$ & $\operatorname{Dev}(\mathrm{df})^{\mathrm{a}}$ \\
\hline 1.1 & $\begin{array}{r}0.0169 \\
\pm 0.0009\end{array}$ & & - & - & - & $2,095(4,909)$ \\
\hline 1.2 & $\begin{array}{l}1.071 \\
\pm 0.37\end{array}$ & & - & $\begin{array}{c}0.072 \\
\pm 0.0063\end{array}$ & - & $1,966(4,908)$ \\
\hline 1.3 & $\begin{array}{r}1.15 \\
\pm 0.39\end{array}$ & $\begin{array}{r}0.0 \\
\pm 0.0\end{array}$ & $\begin{array}{l}00085 \\
0003\end{array}$ & $\begin{array}{c}0.068 \\
\pm 0.0062\end{array}$ & - & $1,938(4,907)$ \\
\hline 1.4 & $\begin{array}{r}0.0387 \\
\pm 0.0030\end{array}$ & & - & - & $\begin{array}{r}0.089 \\
\pm 0.009\end{array}$ & $1,969(4,908)$ \\
\hline 1.5 & $\begin{array}{r}0.0496 \\
\pm 0.0038\end{array}$ & $\begin{array}{r}0.0 \\
\pm 0.0\end{array}$ & $\begin{array}{l}000038 \\
000003\end{array}$ & 一 & $\begin{array}{c}0.081 \\
\pm 0.0084\end{array}$ & $1,950(4,907)$ \\
\hline 1.6 & $\begin{array}{r}0.539 \\
\pm 0.185\end{array}$ & & - & $\begin{array}{r}0.050 \\
\pm 0.007\end{array}$ & $\begin{array}{r}0.064 \\
\pm 0.009\end{array}$ & $1,913(4,907)$ \\
\hline 1.7 & $\begin{array}{r}0.64 \\
\pm 0.22 \\
\end{array}$ & $\begin{array}{r}0.0 \\
\pm 0.0 \\
\end{array}$ & $\begin{array}{l}00048 \\
0002\end{array}$ & $\begin{array}{r}0.048 \\
\pm 0.007\end{array}$ & $\begin{array}{r}0.057 \\
\pm 0.009\end{array}$ & $1,895(4,906)$ \\
\hline \multicolumn{7}{|c|}{$r(a, C)=r_{0}(a)\left(1+\alpha C^{p} \times e^{-\gamma a-\mu \eta+\delta t}\right)$} \\
\hline Model & $\alpha$ & $\mathrm{p}$ & $\gamma$ & $\mu$ & $\delta$ & $\operatorname{Dev}(d f)^{a}$ \\
\hline 2.1 & $\begin{array}{r}4.10 \quad 0 \\
\pm 2.15 \pm 0\end{array}$ & 0.61 & $\begin{array}{c}0.049 \\
\pm 0.0065\end{array}$ & $\begin{array}{c}0.056 \\
5 \pm 0.0092\end{array}$ & - & $1,889(4,906)$ \\
\hline 2.2 & $\begin{array}{r}4.430 \\
\pm 2.31 \pm 0\end{array}$ & $\begin{array}{l}.47 \\
.084\end{array}$ & $\begin{array}{c}0.046 \\
\pm 0.0066\end{array}$ & $\begin{array}{r}0.053 \\
\pm 0.009\end{array}$ & $\begin{array}{r}0.055 \\
\pm 0.016\end{array}$ & $1,878(4,905)$ \\
\hline
\end{tabular}
error. The units year and WLM are used.

${ }^{\mathrm{a}} \mathrm{Dev}=$ deviance; $\mathrm{df}=$ number of degrees of freedom. 
term (Mode. 1.3). Fig. 18 compares the result of the linear-quadratic fit with the rates obtained from the isotonic regression (see Fig. 15); except at high ages and high exposures (in a region with a comparatively small absolute nurnber of lung cancer deaths), the agreement is good.

As age attained $a$ is correlated with time since exposure, it is instructive to alternatively consider the model that accounts only for the latter factor (Models 1.4 and 1.5). This leads, both with the linear and the linear-quadratic expression, to about the same quality of fit as the rnodel that accounts merely for age attained. The age-attained model, and thus the isotonic regression, are therefore a somewhat arbitrary simplification; the role of age attained and of time since exposure are equally important. However, in line with the conclusion of the BEIR IV Committee, there is a further improvement of the fit, if both variables are included in the analysis. Models 1.6 and 1.7 in Table 6 give the results.

In Fig. 19, the results of the linear fit (Model 1.6)
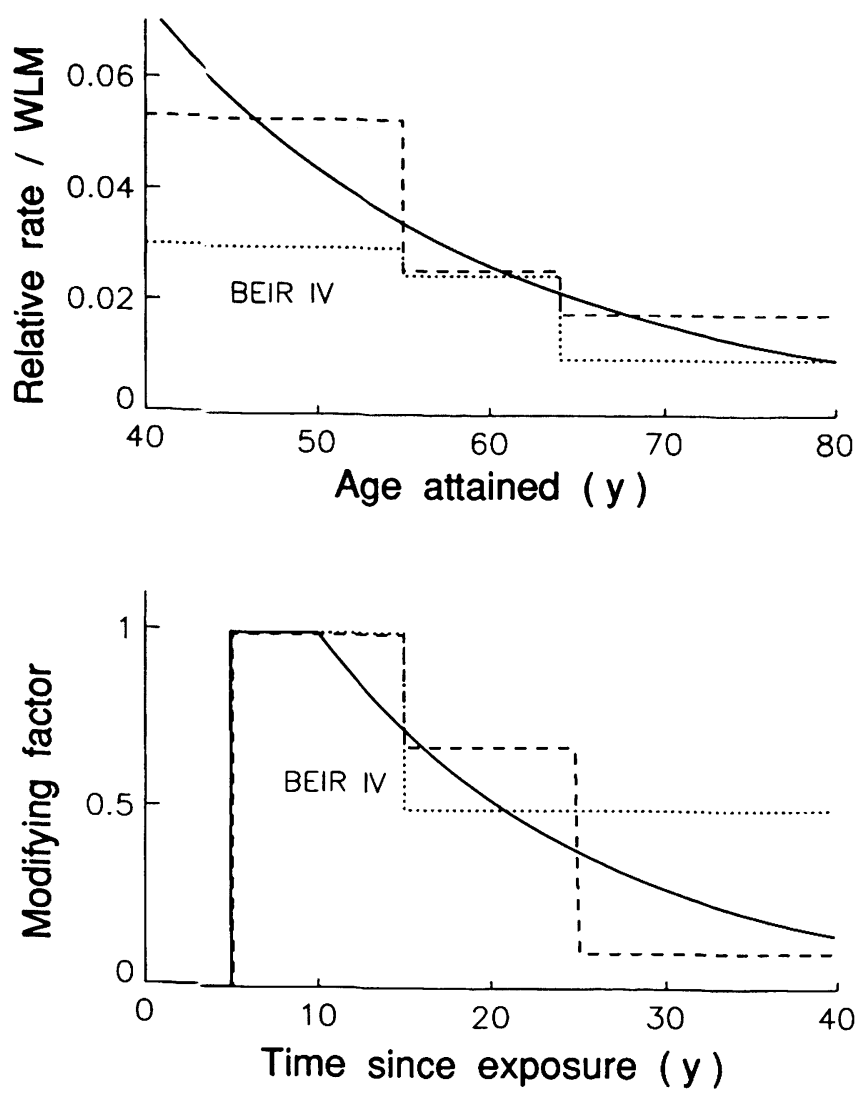

Fig. 19. Comparison between the models used in the BEIR IV report and in the present work. Upper panel: dependence of excess relative rate per WLM on age attained when the term $b(t)=1$; lower panel: time since exposure dependence, $b(t)$; dotted lines: values recommended by the BEIR IV Committee; broken lines: values obtained with the model of the BEIR IV Committee applied to the present data (Table 4); full lines: values obtained with the linear expression corresponding to Model 1.6 in Table 6. (solid lines) are compared with the results obtained by the BEIR IV Committee (dotted lines) and with the results from the present data (broken lines) in terms of the BEIR IV model [see eqn (3)]. The upper panel refe;rs to the age dependencies, and the lower panel to the time since exposure dependencies. Note from the valures in Table 6 that the linear-quadratic model (Model 1.7) gives age and time dependencies that do not substaintially differ from those obtained in the linear modlel 1.6.

\section{The influence of duration of exposure}

Accounting for the added influence of duration, $\tau$, of exposure requires the use of more complicated expressions. Fits of only moderate quality are obtained when exposure duration is combined with linear rellations in cumulated exposure. The use of the linearquadratic relation, together with the added dependencies, is not readily practicable with AMFIT in its current form. For the examination of the additional factors., a relation is employed that contains a single power of exposure. The general model is then as follows:

$$
r(a, C)=r_{o}(a)\left(1+\alpha C^{p} e^{-\gamma a} e^{-\mu \eta} e^{\lambda \tau}\right) .
$$

This can also be written into the notation that is usual with proportional hazards models:

$$
r(a, C)=r_{o}(a)\left(1+\alpha e^{p \ln C-\gamma a-\mu \eta+\lambda \tau}\right) .
$$

Even without the correction for duration of exposure, as seen in Table 6, a fit is obtained that is better than the fit with the linear-quadratic model of eqn (4). The linear-quadratic model may be preferred, in spite of this fact, because it avoids the difficulty of eqn (6), that the slope at $C=0$ is infinite for $p<1$.

While eqn (6) is unsuitable for extrapolation to small exposures, it can bring out the influence of the duration of exposure, $\tau$. The correction term increases the quality of the fit, but it has less influence than the variables age attained or time since median exposure. Other factors being equal, the excess in lung cancer rates appears to be greater for longer duration of exposure. The estimated effect ratio for a durations of exposure of $10 \mathrm{y}$ vs. $5 \mathrm{y}$ is 1.32 .

The apparent nonlinearity, particularly marked at low exposures, could be an artifact. A conceivable explanation is that the miners have received, in addition to their occupational exposures, a nonnegligible domestic exposure but, as stated earlier, this does not seem a likely explanation. It was nevertheless attempted to estimate the average level of added exposure that could account for the nonlinearity. To this purpose the following model was used:

$$
r(a, C)=r_{o}(a)\left[1+\alpha\left(C+C_{o}\right)^{p} e^{-\gamma a}\right],
$$

where $C_{o}$ represents the postulated added exposure. It was found that with $C_{o}$ approximately equal to 100 WLM, the nonlinearity ceases to be significant. This would correspond to an average additional exposure of 
$1010 \mathrm{WLM}$, a value that is too high to be ascribed to an en.hanced domestic exposure.

\section{Liffetime attributable risk}

The results in Table 6 can be translated into lifetime attributable risk (LAR). For this purpose, the excess rates $r_{e}(a, C)$, i.e., $r(a, C)-r_{o}(a)$, from Models $1.6,1.7$, and 2.2 , were integrated over the same life table, based on Swedish data, that has been used as a refference in the latest ICRP recommendations (ICRP 19'91):

$$
L A R=\int_{e+5}^{100} r_{e}(a, C) S(a) d a,
$$

where $S(a)$ is the surviving fraction at age $a, e$ is the age at the beginning of exposure, and $C$ is the lagged cumulated exposure up to age $a$. The examples refer ag:ain to the reference exposure. For the linear and the limear-quadratic model, the dependences on exposure are given in Fig. 20 as broken and as solid lines. The dotted line gives the result for Model 2.2, which also accounts for the duration of exposure.

The right ordinate values in Fig. 20 are given in relative risks, to permit scaling to the actual lifetime lung cancer risk of a specific population. Absolute values are given on the left ordinates; they are scaled to a background rate that corresponds to a lifetime risk of 0.086 for a male population (see Fig. 5).

\section{CONCLUSIONS}

The primary aim of this study is the presentation of a complex data set in terms of a series of diagrams that permit an appreciation of the various factors that are involved in the increase of lung cancer mortality among the uranium miners of the S-cohort. An elementary analysis is presented which shows that the observed number of 574 lung cancer deaths up to 1,985 exceeds the expected number of 122 by almost a factor

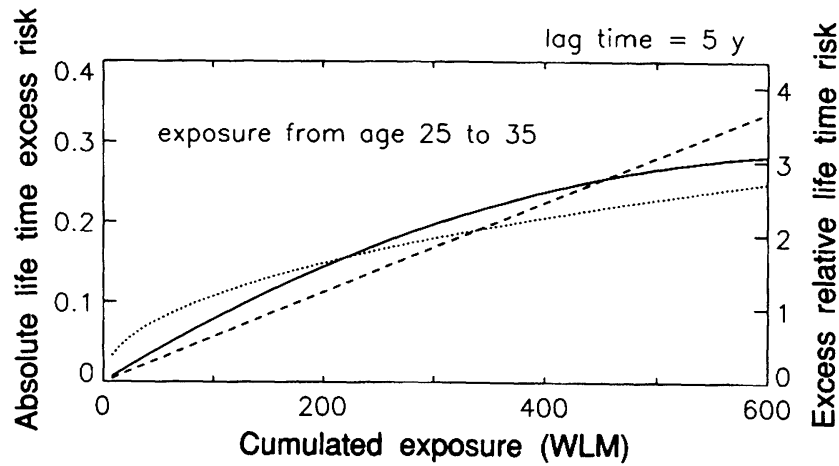

Fig. 20. Lifetime attributable excess risk for lung cancer deaths vs. cumulated exposure. Full line: linear quadratic model (Model 1.7 in Table 6); broken line: linear model (Model 1.6 in Table 6); dotted line: complete model (Model 2.2 in Table 6). of 5. The mean cumulated exposure is 225 WLM, and a linear extrapolation would, therefore, indicate a doubling exposure of about 95 WLM. The data indicate, however, a higher effectiveness per WLM at low exposures, and this suggests even lower exposures for doubling the lung cancer rates.

The elementary analysis is extended by the use of isotonic regression. This type of analysis determines, without postulated analytical expressions, the dependence of the lung cancer mortality rate on age attained and cumulated exposure. The results of the isotonic regression support the conclusion that the excess lung cancer mortality per WLM is largest at small exposures. The cumulated exposure that doubles the lung cancer mortality rate appears to be as low as 30 to 40 WLM, at ages between 55 and $70 \mathrm{y}$.

Parametric models are used in the last part of the analysis. They are only partly equal to those used by the BEIR IV Committee, but they follow generally the same approach as its external analysis. The BEIR IV Committee concluded from these results that the most important factors influencing the lung cancer mortality rate are cumulated exposure, attained agc, and time since exposure. The dependence on time since exposure means, in agreement with the analyses of the BEIR IV Committee, that a given exposure causes less effect at a specified attained age, if it has occurred at an earlier age. Using a model that is linear in cumulated exposure, and calculating lifetime attributable risk, the present data show an absolute excess risk of $0.05 \% \mathrm{WLM}^{-1}$ and an excess relative risk of $0.6 \% \mathrm{WLM}^{-1}$.

While the analysis has made it possible to separate and quantify the influence of several factors, it must also be noted that the present results are based on the follow-up of miners who have been at work predominantly at ages between $20 \mathrm{y}$ and $40 \mathrm{y}$. To extrapolate any of the findings beyond a male population exposed at such ages would be unwarranted.

The duration of exposure is a somewhat less important added factor that has not consistently been seen in the BEIR IV analysis. However, for the cohort of the Colorado Plateau, a similar dependence has been reported (Hornung and Samuels 1981; Hornung and Meinhardt 1987). As in this cohort, and also in the

${ }^{224} \mathrm{Ra}$ patients (Chmelevsky et al. 1990), protraction of an exposure is, in the present data, associated with larger cancer excess risk. However, a more thorough analysis will be required to determine whether this is an inherent "protraction effect" or a mere association with an, as yet, unrecognized confounding factor.

The dependence of the excess lung cancer risk appears to be steepest at low exposures, i.e., the relation is nonlinear. The observed supralinearity of the dependence of the excess risk on exposure is not an artifact of the temporal distribution of exposures. As seen in Fig. 10, the mean cumulated exposure of the miners is about proportional to their duration of work, i.e., the "mean exposures rates" are about the same for the groups with different total exposure. If, instead, the 
duration of exposure would be the same, irrespective of total exposure, the effectiveness ratio between high and low exposure would be further reduced (i.e., the supralinearity would be even more marked). Furthermore, it is unlikely that the apparent nonlinearity results from above-average domestic radon exposures. However, it cannot be excluded that the observation is an artifact of other confounders, and it would, therefore, be premature to abandon the common postulate of a linear relation between exposure and excess cancer rate.

Acknowledgements-We thank D. L. Preston for kindly advising us in the extended use of his program package EPICURE.

\section{REFERENCES}

Agricola, G. (1597) De Re Metallica. Hoover, H. C.; Hoover, L. H., translators. New York, Basel: Dover Publications; 1950.

Barlow, R. E.; Bartholomew, D. J.; Bremner, J. M.; Brunk, H. D. Statistical inference under order restrictions; the theory and application of isotonic regression. New York: John Wiley and Sons; 1972.

Chmelevsky, D.; Spiess, H.; Mays, C. W.; Kellerer, A. M. The reverse protraction factor in the induction of bone sarcomas in radium-224 patients. Rad. Res. 12:69-79; 1990.

Gebhardt, F. An algorithm for monotone regression with one or more independent variables. Biometrika 57:263-271; 1970.

Horácek, J.; Placek, V.; Sevc, J. Histologic types of bronchogenic cancer in relation to different conditions of radiation exposure. Cancer 40:832; 1977.

Hornung, R. W.; Meinhardt, T. J. Quantitative risk assessment of lung cancer in U.S. uranium miners. Health Phys. $52: 417-430 ; 1987$.

Hornung, R. W.; Samuels. S. Survivorship models for lung cancer mortality in uranium miners. Is cumulative dose an appropriate measure of exposure? In: Gomez, M., ed. Radiation hazards in mining: Control, measurement and medical aspects. New York: American Institute of Mining, Metallurgical and Petroleum Engineers Inc; 1981.

International Commission on Radiological Protection. Lung cancer risk from indoor exposures to radon daughters. Oxford: Pergamon Press; Ann. ICRP Publication 50; 1986.

International Commission on Radiological Protection. 1990 Recommendations of the International Commission on Radiobiological Protection. Oxford: Pergamon Press; ICRP Publication 60; 1991.

Kubík, A. Studies on smoking, chronic non-specific respiratory diseases and lung cancer in selected territories of Czechoslovakia. Z. Erkrank. Am. Org. 152:180; 1979.

Kunz, E.; Sevc, J.; Placek, V. Lung cancer mortality in uranium miners. Health Phys. 35:579-580; 1978.

Kunz, E.; Sevc, J.; Placek, V.; Horácek, J. Lung cancer in man in relation to different time distributions of radiation exposure. Health Phys. 36:699-706; 1979.

Lubin, J. H. Models for the analysis of radon-exposed popiulations. Yale J. Biol. Med. 61:195-214; 1988.

Lubin, J. H.; Gaffey, W. Relative risk models for assessing the joint effects of multiple factors. Am. J. Ind. Med. 13:149-167; 1988.

National Research Council, Committee on the Biological Effects of Ionizing Radiations (BEIR IV). Health risks of radon and other internally deposited alpha emitters. Wasihington, DC: National Academy Press; 1988.

Sevc, J. Conception and results of Czechoslovak epidemiological studies. Veröffentlichung der Strahlenschutzkommission, Band 21. Stuttgart, New York: Gustav Fischer; in press.

Sevc, J.; Kunz, E.; Placek, V. Lung cancer in uranium miners and long-term exposure to radon daughter products. Health Phys. 30:433-437; 1976.

Sevc, J.; Kunz, E.; Tomásek, L.; Placek, V.; Horácek, J. Cancer in man after exposure to $\mathrm{Rn}$ daughters. Heallth Phys. 54:27-46; 1988.

Sevc, J.; Tomásek, L.; Placek, V.; Horácek, J.; Kunz, E.; Smid A., Vernerová, P.; Sedlák, A.; Kransová, M. Lung cancer and inhalation radiation exposure (final report of a study). Prague: Institute of Hygiene and Epidemiology; and Pribram, Kamenná, Czechoslovakia: Institute of Industrial Hygiene in Uranium Industry; 1983.

Sevc, J.; Tomaśek, L.; Skokanová, K.; Stromp, L. Epidemiological studies in miners exposed to low levels of radon daughters. In: Proceedings of the 2nd International Symposium on Occupational Health and Safety in Mining and Tunnelling; 23-26 September 1986, Prague: Czechoslovak Medical Society; 1986.

\section{APPENDIX}

Tables of person-years and lung cancer deaths in the S-cohort.

\section{Table 1A}

The number of person-years at risk distributed in age and in cumulated exposure (lagged by $5 \mathrm{y}$ ).

The width of the age scale is $2.5 \mathrm{y}$. The logarithmic width of the scale of cumulated exposure is 0.23 . Central values of the age and exposure values, rounded to the next integer, are given in the top line and the left hand column. The lowest line corresponds to miners with lagged cumulated exposure less than 13 WLM.

Observations beyond age 80 are not utilized in the computations. Person-years at risk below age 27.5 and above cumulated exposure to 1033 WLM are omitted in the Table (and in Tables 2A, 2 and 3), although they are used in the computations; no lung cancer deaths have occurred in these ranges of age and cumulated exposure.

\section{Table 2A}

Observed lung cancer deaths in the cells corresponding to Table $1 \mathrm{~A}$. 
Table 1A. Person-years.

\begin{tabular}{crrrrrrrrrrrrrrrrrrrr}
\hline $\begin{array}{c}\text { Exposure } \\
\text { (WLM) }\end{array}$ & 29 & 32 & 34 & 37 & 39 & 42 & 44 & 47 & 49 & 52 & 54 & 57 & 59 & 62 & 64 & 67 & 69 & 72 & 74 & 77 \\
\hline 920 & 1 & 2 & 5 & 12 & 23 & 19 & 36 & 30 & 44 & 34 & 67 & 46 & 63 & 35 & 42 & 25 & 30 & 18 & 17 & 10 \\
731 & 15 & 19 & 47 & 44 & 102 & 73 & 115 & 90 & 159 & 111 & 155 & 104 & 135 & 78 & 100 & 56 & 57 & 31 & 33 & 13 \\
581 & 20 & 41 & 112 & 121 & 219 & 175 & 319 & 232 & 389 & 258 & 377 & 238 & 323 & 180 & 198 & 74 & 83 & 42 & 40 & 12 \\
461 & 62 & 56 & 176 & 163 & 292 & 229 & 353 & 262 & 388 & 277 & 458 & 285 & 371 & 218 & 244 & 123 & 143 & 76 & 70 & 30 \\
366 & 79 & 106 & 240 & 182 & 330 & 258 & 464 & 353 & 561 & 384 & 544 & 354 & 462 & 251 & 287 & 143 & 147 & 66 & 63 & 31 \\
291 & 109 & 119 & 252 & 259 & 456 & 378 & 660 & 495 & 785 & 562 & 808 & 490 & 619 & 336 & 385 & 166 & 169 & 77 & 74 & 28 \\
231 & 112 & 122 & 332 & 310 & 641 & 485 & 859 & 616 & 977 & 660 & 945 & 570 & 726 & 386 & 440 & 196 & 203 & 89 & 88 & 35 \\
184 & 137 & 190 & 432 & 428 & 787 & 640 & 1,056 & 726 & 1,126 & 748 & 1,050 & 657 & 807 & 438 & 520 & 238 & 273 & 138 & 135 & 51 \\
146 & 171 & 203 & 615 & 549 & 951 & 752 & 1,178 & 803 & 1,298 & 793 & 1,126 & 665 & 835 & 450 & 523 & 278 & 304 & 150 & 153 & 61 \\
116 & 223 & 321 & 790 & 637 & 1,119 & 833 & 1,342 & 966 & 1,449 & 962 & 1,307 & 757 & 906 & 495 & 565 & 267 & 297 & 149 & 142 & 51 \\
92 & 237 & 299 & 664 & 499 & 819 & 556 & 815 & 563 & 827 & 539 & 766 & 435 & 525 & 258 & 305 & 139 & 143 & 61 & 56 & 23 \\
73 & 193 & 288 & 465 & 302 & 459 & 287 & 426 & 322 & 461 & 297 & 441 & 245 & 287 & 166 & 199 & 104 & 120 & 56 & 58 & 28 \\
58 & 213 & 262 & 333 & 195 & 350 & 205 & 287 & 195 & 293 & 198 & 241 & 134 & 164 & 87 & 101 & 47 & 66 & 30 & 22 & 10 \\
46 & 218 & 206 & 242 & 171 & 246 & 133 & 207 & 140 & 219 & 139 & 165 & 100 & 121 & 71 & 74 & 38 & 36 & 17 & 18 & 9 \\
37 & 159 & 134 & 187 & 105 & 176 & 79 & 138 & 108 & 140 & 80 & 113 & 72 & 88 & 48 & 57 & 29 & 37 & 16 & 18 & 6 \\
29 & 138 & 81 & 120 & 87 & 115 & 54 & 76 & 47 & 66 & 40 & 66 & 28 & 40 & 26 & 22 & 6 & 10 & 4 & 6 & 4 \\
23 & 110 & 86 & 96 & 64 & 75 & 50 & 76 & 51 & 61 & 35 & 40 & 21 & 19 & 10 & 6 & 4 & 1 & 0 & 0 & 0 \\
18 & 98 & 74 & 71 & 61 & 58 & 29 & 57 & 23 & 46 & 28 & 36 & 18 & 17 & 5 & 6 & 2 & 2 & 0 & 0 & 0 \\
15 & 56 & 51 & 56 & 34 & 48 & 22 & 43 & 28 & 24 & 21 & 25 & 9 & 12 & 10 & 8 & 4 & 2 & 0 & 0 & 0 \\
0 & 591 & 371 & 597 & 300 & 236 & 169 & 355 & 170 & 196 & 132 & 171 & 56 & 46 & 16 & 21 & 5 & 1 & 0 & 0 & 0 \\
\hline
\end{tabular}

Table 2A. Lung-cancer deaths.

\begin{tabular}{|c|c|c|c|c|c|c|c|c|c|c|c|c|c|c|c|c|c|c|c|c|c|}
\hline \multirow{2}{*}{$\begin{array}{l}\text { Exposure } \\
\text { (WLM) }\end{array}$} & \multicolumn{21}{|c|}{ Age $(y)$} \\
\hline & 29 & 32 & 34 & 37 & 39 & 42 & 44 & 47 & 49 & 52 & 54 & 57 & 59 & 62 & 64 & 67 & 69 & 72 & 74 & 77 & 79 \\
\hline 920 & . & . & . & . & 1 & & & & 1 & & 2 & 1 & 0 & 1 & 1 & 1 & & . & & & . \\
\hline 731 & • & & & & 0 & 2 & 1 & 0 & 2 & 4 & 2 & 0 & 3 & 0 & 2 & 2 & 2 & . & 1 & & . \\
\hline 581 & & $i$ & 0 & 1 & 1 & 0 & 2 & 3 & 5 & 5 & 4 & 5 & 7 & 1 & 9 & 1 & 1 & & 1 & $i$ & . \\
\hline 461 & 0 & 0 & 0 & 1 & 1 & 1 & 5 & 4 & 5 & 2 & 3 & 5 & 4 & 4 & 2 & 3 & 0 & $i$ & 1 & & . \\
\hline 366 & 0 & 0 & 0 & 0 & 2 & 0 & 0 & 3 & 3 & 4 & 10 & 2 & 3 & 7 & 4 & 1 & 5 & 2 & 0 & 1 & . \\
\hline 291 & 0 & 0 & 1 & 0 & 2 & 3 & 4 & 2 & 3 & 7 & 12 & 2 & 5 & $i$ & 7 & 3 & 1 & 2 & 0 & & 1 \\
\hline 231 & 0 & 0 & 0 & 1 & 1 & 2 & 1 & 3 & 4 & 6 & 10 & 4 & 7 & 8 & 5 & 5 & 7 & 1 & 0 & & \\
\hline 184 & 0 & 0 & 3 & 0 & 0 & 4 & 4 & 2 & 3 & 8 & 9 & 5 & 8 & 7 & 8 & 2 & 4 & 2 & 2 & 0 & 1 \\
\hline 146 & 0 & 1 & 1 & 0 & 1 & 0 & 2 & 3 & 7 & 5 & 11 & 6 & 14 & 6 & 6 & 8 & 5 & 0 & 0 & 0 & 0 \\
\hline 116 & 0 & 0 & 0 & 0 & 1 & 0 & 1 & 5 & 5 & 5 & 7 & 3 & 6 & 6 & 5 & 5 & 3 & 2 & 1 & 2 & \\
\hline 92 & 0 & 0 & 0 & 0 & 2 & 0 & 4 & 2 & 3 & 3 & 0 & 2 & 5 & 1 & 4 & 3 & 1 & 0 & 0 & & 1 \\
\hline 73 & 0 & 1 & 0 & 0 & 0 & 0 & 1 & 1 & 3 & 3 & 5 & 1 & 1 & 1 & 0 & 1 & 2 & 0 & 0 & & \\
\hline 58 & 0 & 0 & 0 & 0 & 0 & 1 & 0 & 0 & 1 & 0 & 1 & 2 & 0 & 0 & 1 & & 2 & . & . & . & ${ }^{\circ}$ \\
\hline 46 & 0 & 0 & 0 & 0 & 0 & 0 & 0 & 0 & 1 & 0 & 0 & 1 & 1 & 2 & 0 & $i$ & . & . & . & . & . \\
\hline 37 & 1 & 0 & 0 & 0 & 1 & 0 & 0 & 0 & 1 & 0 & 0 & 1 & 0 & 2 & 1 & 2 & . & . & : & : & . \\
\hline 29 & 0 & 0 & 0 & 0 & 0 & 0 & 0 & 1 & 0 & 1 & 0 & 1 & 0 & . & 1 & & . & : & $:$ & & . \\
\hline 23 & 0 & 0 & 0 & 0 & 0 & 0 & 0 & 0 & 0 & & & . & . & . & . & . &. & : & . & . & . \\
\hline 18 & 0 & 0 & 0 & 0 & 0 & & 0 & & & & 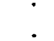 & & & $\cdot$ & i & & & : & : & & \\
\hline 15 & 0 & 0 & 0 & & & & & & 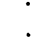 & $i$ & & & i & i & : & : & $i$ & : & : & i & . \\
\hline 0 & 0 & 0 & 0 & 0 & 0 & 0 & 0 & $i$ & $i$ & 0 & 0 & 0 & & . & . & 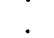 & & . & . & ${ }^{\circ}$ & . \\
\hline
\end{tabular}

